\title{
Ochratoxin A: The Continuing Enigma
}

\author{
Evelyn O'Brien and Daniel R. Dietrich \\ Environmental Toxicology, University of Konstanz, Germany
}

\begin{abstract}
The mycotoxin ochratoxin A (OTA) has been linked to the genesis of several disease states in both animals and humans. It has been described as nephrotoxic, carcinogenic, teratogenic, immunotoxic, and hepatotoxic in laboratory and domestic animals, as well as being thought to be the probable causal agent in the development of nephropathies (Balkan Endemic Nephropathy, BEN and Chronic Interstitial Nephropathy, CIN) and urothelial tumors in humans. As a result, several international agencies are currently attempting to define safe legal limits for OTA concentration in foodstuffs (e.g., grain, meat, wine, and coffee), in processed foods, and in animal fodder. In order to achieve this goal, an accurate risk assessment of OTA toxicity including mechanistic and epidemiological studies must be carried out. Ochratoxin has been suggested by various researchers to mediate its toxic effects via induction of apoptosis, disruption of mitochondrial respiration and/or the cytoskeleton, or, indeed, via the generation of DNA adducts. Thus, it is still unclear if the predominant mechanism is of a genotoxic or an epigenetic nature. One aspect that is clear, however, is that the toxicity of OTA is subject to and characterized by large species- and sex-specific differences, as well as an apparently strict structure-activity relationship. These considerations could be crucial in the investigation of OTA-mediated toxicity. Furthermore, the use of appropriate in vivo and in vitro model systems appears to be vital in the generation of relevant experimental data. The intention of this review is to collate and discuss the currently available data on OTA-mediated toxicity with particular focus on their relevance for the in vivo situation, and also to suggest possible future strategies for unlocking the secrets of ochratoxin A.
\end{abstract}

Keywords Kidney, Mechanism, Nephropathy, Ochratoxin A

\section{BACKGROUND}

Of the myriad of currently known mycotoxins only a handful have been adequately characterized. Even the name is a partial misnomer, originating from the ancient Greek " $\mu \nu \kappa \eta \delta$ " (fun-

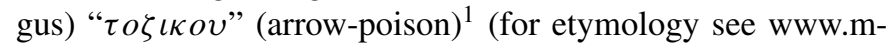
w.com). These substances are secondary metabolites produced by a number of molds, including members of the Aspergillus, Penicillium, Fusarium, Claviceps, and Alternaria families. Of the many proposed reasons for their production, the suggestions of facilitated competition with other microorganisms for nutrients and space and the generation of favorable germination conditions for fungal spores ${ }^{2,3}$ are arguably the most likely candidates. Whichever the case may be, mycotoxins have been responsible for large financial losses in conjunction with contaminated and thus unsafe agricultural products as well as being the cause of diseases in both humans and animals.

Address correspondence to Evelyn O'Brien, Environmental Toxicology, University of Konstanz, Jacob-Burckhardt Str. 25, Konstanz, D-78457, Germany. E-mail: evelyn.obrien@uni-konstanz.de; web site www.umwelttoxikologie.uni-konstanz.de
One of these, ochratoxin A (OTA), has been implicated in a diverse range of toxicological effects, including renal toxicity, mutagenicity, teratogenicity, neurotoxicity, and immunotoxicity, to name but a few, in both animals and humans. Based on animal studies and epidemiological studies in human populations (described later), OTA has been classified as a class $2 \mathrm{~B}$ carcinogen (possible human carcinogen) by the IARC. ${ }^{4}$ Maximum permissible OTA concentrations of 5 and $3 \mu \mathrm{g} / \mathrm{kg}$ in raw cereals and processed cereal products, respectively, are currently under debate by several countries including the United States ${ }^{5}$ and the member states of the European Union. ${ }^{6-8}$ Difficulties in the interpretation of the available data and conflicts with respect to standards for commodity products (e.g., coffee, beer, wine, etc.) in international trade are, however, making agreement difficult.

Several newspaper reports ${ }^{9-11}$ and articles in popular science and consumer magazines ${ }^{12-15}$ have raised public awareness of the potential health risks posed by mycotoxins and, in particular, by ochratoxin contamination of human and animal foodstuffs, making the elucidation of the mechanisms of action and hence a more reliable risk assessment imperative.

The diversity of toxic actions associated with ochratoxins has naturally led to a wealth of research being carried out into 
this topic, yet many discrepancies and arguments still exist as to the mechanism of action of members of the ochratoxin family and their potential risk to human health. In the face of such difficulties, it is an arduous task to maintain perspective and to reconcile the effects observed in one aspect of ochratoxinmediated toxicity with those in another. It is therefore the goal of this review to collate the currently available information and opinions on OTA-mediated toxicity and possibly indicate new strategies for future ochratoxin research.

\section{Production and Properties}

While a complete review of the production and chemistry of ochratoxins is not the intention of this text, a brief overview is provided. Several papers and reviews dealing with these aspects are available. ${ }^{1,16-18}$ The family of ochratoxins consists of three members, A, B, and C (see Figure 1), which are produced by several molds of the Aspergillus and Penicillium species (in particular Aspergillus ochraceus) under suitable conditions of temperature $\left(21-28^{\circ} \mathrm{C}\right.$ and $25-28^{\circ} \mathrm{C}$ for Penicillium and Aspergillus species, respectively) and humidity $\left(a_{\mathrm{w}}>0.7\right) .{ }^{19-21}$ This can lead to field and storage contamination of, for example, of maize and of grain and grain products and via a carryover effect of meat, in particular pork. Ochratoxins are relatively heat stable; baking and roasting reduce the toxin content by a mere $20 \%$, while boiling has no effect. ${ }^{22,23}$ Due to the ubiquitous nature of the producing fungi, ochratoxins are found regularly as contaminants of animal fodder and human provisions as diverse as muesli, coffee, and wine. ${ }^{24}$ Indeed, the consumption of certain red wines has been shown to surpass the recommended virtually safe dose (see below) by a factor of $20,{ }^{9}$ and total avoidance of ochratoxin consumption is practically impossible.

Chemically, ochratoxins are weak organic acids consisting of a dihydroisocumarin moiety joined by a peptide bond to 1phenylalanine (see Figure 1). Structurally, the three toxins differ only very slightly from each other; however, these differences have marked effects on their respective toxic potentials, with ochratoxin A (OTA) being both the most commonly detected and the most toxic of the three. Substitution of chloride for a hydrogen atom in the isocumarin moiety yields ochratoxin B (OTB), which is significantly (10- to 20 -fold) less toxic both in vivo and in vitro. Further structural alterations yield ochratoxin $\mathrm{C}$ (OTC), which is generally perceived as having little or no toxic potential. ${ }^{25-27}$ However, a recent publication has reported OTC to possess a far greater toxic potential than either OTA or OTB in the human monocyte cell line THP- $1 .^{28}$ In light of previously published data, this may be a cell-type specific effect. It appears, therefore, that strict structure-activity relationships are a feature of ochratoxin toxicity. Due to its role as the most toxic of the family members, much research has focussed on OTA. This review also concentrates primarily on this aspect. It should not, however, be forgotten that exploitation of the clear differences in the effects of OTA, OTB and OTC could indeed provide the key to unlocking the secrets of this enigmatic family of mycotoxins.
TABLE 1

Selected $\mathrm{LD}_{50}$ values and half-lives of OTA in relevant species following oral administration

\begin{tabular}{lcll}
\hline Species & $\begin{array}{c}\text { Oral LD } \\
(\mathrm{mg} / \mathrm{kg} \mathrm{b} . w .)\end{array}$ & \multicolumn{1}{c}{$t_{1 / 2}(\mathrm{po})$} & References \\
\hline Human & n.d. & 35.5 days & 60 \\
Monkey & n.d. & 21 days & 29 \\
Pig & $1.0-6.0$ & $72-120 \mathrm{hrs}$ & 30,31 \\
Rat & $20-30$ & $55-120 \mathrm{hrs}$ & 30,32 \\
Mouse & $48-58$ & $40 \mathrm{hrs}$ & 29,34 \\
\hline
\end{tabular}

Note. $t_{1 / 2}$ Varies considerably with the route of administration; n.d., no data available

\section{Acute Toxicity, Chronic Nephropathy, and Renal Carcinogenesis}

Acute Toxicity

Both the acute toxicity and half-life of OTA are relatively low and characterized by large species differences in sensitivity (Table 1). Oral $\mathrm{LD}_{50}$ values have been demonstrated to range from approximately 20 and $46-58 \mathrm{mg} / \mathrm{kg}$ body weight (b.w.) in rats and mice, respectively, to $0.2-1 \mathrm{mg} / \mathrm{kg} \mathrm{b} . \mathrm{w}$ in pigs, cats, rabbits, and dogs. ${ }^{29-34}$ In these studies the symptoms of acute poisoning included multifocal haemorrhaging in almost all major organs and fibrin thrombi in the spleen, brain, liver, kidney, and heart. Nephrosis, necrosis in the liver and lymphoid tissues, and enteritis with coincident villious atrophy were also apparent in all species examined. ${ }^{35}$ A single anecdotal case of probable acute OTA toxicity in humans has been reported in southern Italy, ${ }^{36}$ where one individual presented with transitory epigastric tension, respiratory distress, and retrosternal burning following working in a granary that had been closed for 2 years. A biopsy revealed acute tubular necrosis, and although the patient's blood was not analyzed for the presence of OTA, the toxin was determined (thin-layer chromatography) to be present in wheat from the storage silo.

It is, however, rather the subchronic and chronic effects of OTA that are of greatest concern. OTA is considered the causal agent in nephropathies observed in several species of agricultural animals, particularly in pigs, ${ }^{37,38}$ resulting in huge financial losses in agriculture and in the food industry. These effects have already been reviewed in Marquardt and Frohlich ${ }^{39}$ and references therein. The immunotoxic, hepatotoxic, and teratogenic effects attributed to OTA, while less prominent, may have an equally large impact on socioeconomic factors. Indeed, recent heightened awareness of the potential losses for the agriculture industry through the immunotoxic, hepatotoxic, and teratogenic effects of OTA has resulted in an increased incentive for research in these areas (discussed later).

\section{OTA and Human Disease}

OTA has also been associated with two human disease states: Balkan endemic nephropathy (BEN) and urothelial tumors (UT). 


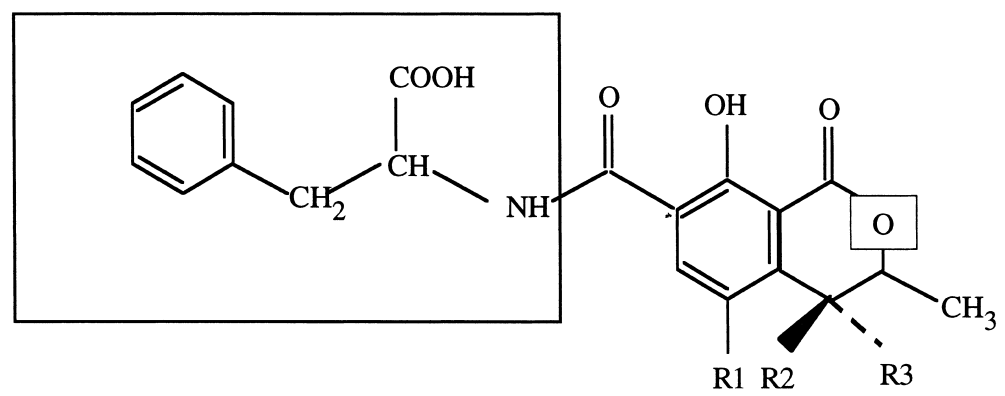

$\begin{array}{lllll}\text { Analogue } & \text { R1 } & \text { R2 } & \text { R3 } & \text { Box } \\ \text { OTA } & \text { Cl } & \text { H } & \text { H } & \text { Phenylalanine } \\ \text { OTB } & \text { H } & \text { H } & \text { H } & \text { Phenylalanine } \\ \text { OTC } & \mathrm{Cl} & \text { H } & \text { H } & \text { Phenylalanine ethyl ester }\end{array}$

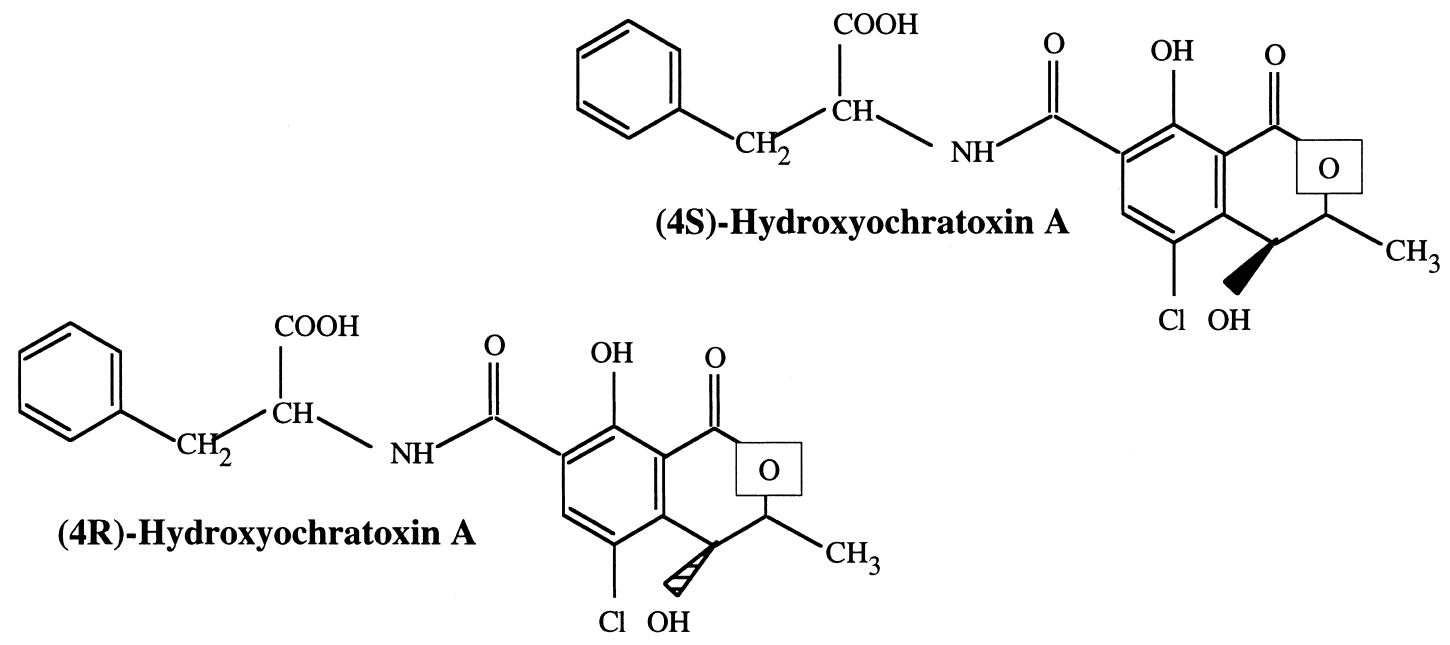<smiles>CCCCCCCCC(N)C(=O)NC(C)Cc1ccccc1</smiles>

FIG. 1. Chemical structures of ochratoxins and major metabolites. The members of the ochratoxin family are structurally extremely similar. Yet these slight alterations play a large role in the relative toxicity of the individual substances. As aspartame has been suggested to competitively reduce OTA-mediated toxicity, its structure is also included for comparison. 
BEN is a chronic progressive kidney disease, first described almost 50 years ago for populations in the lowland regions of the Danube basin and in neighboring areas along the river Sava in Croatia. ${ }^{40,41}$ Currently, BEN represents $11 \%$ of all primary renal diseases diagnosed in the former Yugoslavia (for comparison, diabetic nephropathy represents only $7 \%) .{ }^{42} \mathrm{BEN}$ is characterized by progressive tubulointerstitial nephropathy, leading to tubular atrophy, periglomerular fibrosis, and cortical cysts, inevitably progressing to degenerative and necrotic renal epithelia, hyperplastic arteriopathy, and end-stage renal failure. ${ }^{41,43}$ The accompanying functional deficits in the early stages of the disease, which begins without an acute episode, include increased urinary concentrations of glucose, proteins, leucine aminopeptidase, and $\gamma$-glutamyl transferase, coupled with a decrease in serum cholesterol and protein concentration. Creatinine clearance rates and urinary specific gravity are markedly reduced. The malignant tumors of the upper urinary tract that often accompany BEN are extremely aggressive in nature ${ }^{43,44}$ and some studies have indicated a very slightly higher incidence of the disease in females. Although a direct link between BEN/UT and OTA remains to be established, epidemiological data correlates a moderate increase in serum OTA levels with a significantly higher incidence of nephropathy and urothelial tumors in humans. Studies carried out in several countries including Tunisia, Egypt and France, where climatic conditions and/or suboptimal storage of grain and grain products promote OTA production by fungal species, have also indicated a link between dietary intake of OTA and the development of renal and urothelial tumors. ${ }^{41,45-50}$

\section{Disease in Pigs}

Since its demonstration by Krogh and coworkers ${ }^{37}$ as the probable causative factor in Danish (and probably Bulgarian) porcine nephropathy, the nephrotoxic activity of OTA has become the focus of much attention. The lesions caused by chronic OTA exposure in pigs are characterized by progressive tubular atrophy coupled with proliferation of fibroblastic connective tissue, progressing to activation and proliferation of vascular endothelial and adventitial cells. ${ }^{51}$ Not only does this result in reduced food intake and hence reduced weight gain by the animals but, based on the association with BEN and UT in humans, detection of OTA leads in certain countries, particularly in Scandinavia, to the condemnation of meat from contaminated animals as unfit for human consumption.

Functional deficits in pigs resulting from OTA exposure have been shown to include increased urinary concentrations of glucose, proteins, leucine aminopeptidase, and $\gamma$-glutamyl transferase coupled with a decrease in serum cholesterol and protein concentration. As is the case for BEN, creatinine clearance rates and urinary specific gravity are also markedly reduced. These deficits are reflected in the pathological changes, which occur in the kidneys of exposed animals. The proximal tubules are the initial site of attack, displaying a dose- and time-dependent irreversible desquamation and focal degeneration of the epithelial cells coupled with focal peritubular fibrosis and thickening of the basement membrane. ${ }^{37,52,53}$ In contrast to the findings in humans and in rats (discussed later), no increased tumor incidence has been observed in pigs following OTA exposure. This is probably due to the relatively long latent period of tumorigenesis coupled with the relatively young age at which pigs are slaughtered. The parallels between the pathological changes and functional deficits observed in pigs and those noted in human $\mathrm{BEN} / \mathrm{UT}$ cases have resulted in numerous investigations into the causative role of OTA in human disease.

\section{Rodent Renal Pathologies}

A clear causative relationship has been established between OTA exposure and the development of renal pathologies in rodents. A 2-year carcinogenesis study carried out by Boorman and coworkers ${ }^{54}$ demonstrated a $60 \%$ incidence of renal-cell carcinoma (RCC), coupled with a distinct pathology of the pars recta (P3), which became apparent following 9 months of exposure of male rats to OTA. Although no UTs were reported in this study, the renal cortex of exposed animals presented with degeneration of the tubular epithelium of the renal cortex and the outer medulla, as well as protein casts, karyomegalic nuclei, and renal cortical cysts, which were distinct from those commonly noted in aging rats (see Figure 2). Hyperplastic lesions progressed to malignant renal cell adenomas and carcinomas, which were often multiple and bilateral. Remarkably, female rats displayed only a 6\% tumor incidence and a much milder $\mathrm{P} 3$ pathology under the same experimental conditions. Even starker differences in the response of mice to OTA exposure were demonstrated by Bendele and colleagues, ${ }^{55}$ with only $28 \%$ of male mice developing renal tumors and females being totally refractive, despite being exposed to a 20 -fold higher concentration of OTA than that employed in Boorman's study with F344 rats. The higher sensitivity of males in these studies is clearly in contrast with the suggestion from epidemiological studies that female humans are more at risk. However, attempts to explain these sex differences have been unsuccessful to date. The observations that the complement of organic anion transporter molecules can vary with species, sex, and/or age (see below) could possibly provide clues to the origin of these sensitivity differences.

The aforementioned studies carried out by Boorman and Bendele and their respective coworkers were used to generate the currently accepted virtually safe dose (VSD) for human renal cancer risk of $0.2 \mathrm{ng} / \mathrm{kg} / \mathrm{day}$. Two important considerations were however omitted in the calculation of this dose. Rodents primarily excrete OTA via the billiary route, whereas renal excretion dominates in humans. ${ }^{56-58}$ Thus, the concentrations of OTA reaching the human kidney are probably far higher than those in rodents. Arguably more critical is the observed half-life of OTA in the various species tested to date (Table 1), which in humans, with 35.3 days, is approximately 14 times longer than that in the rat. $27,59,60$ 

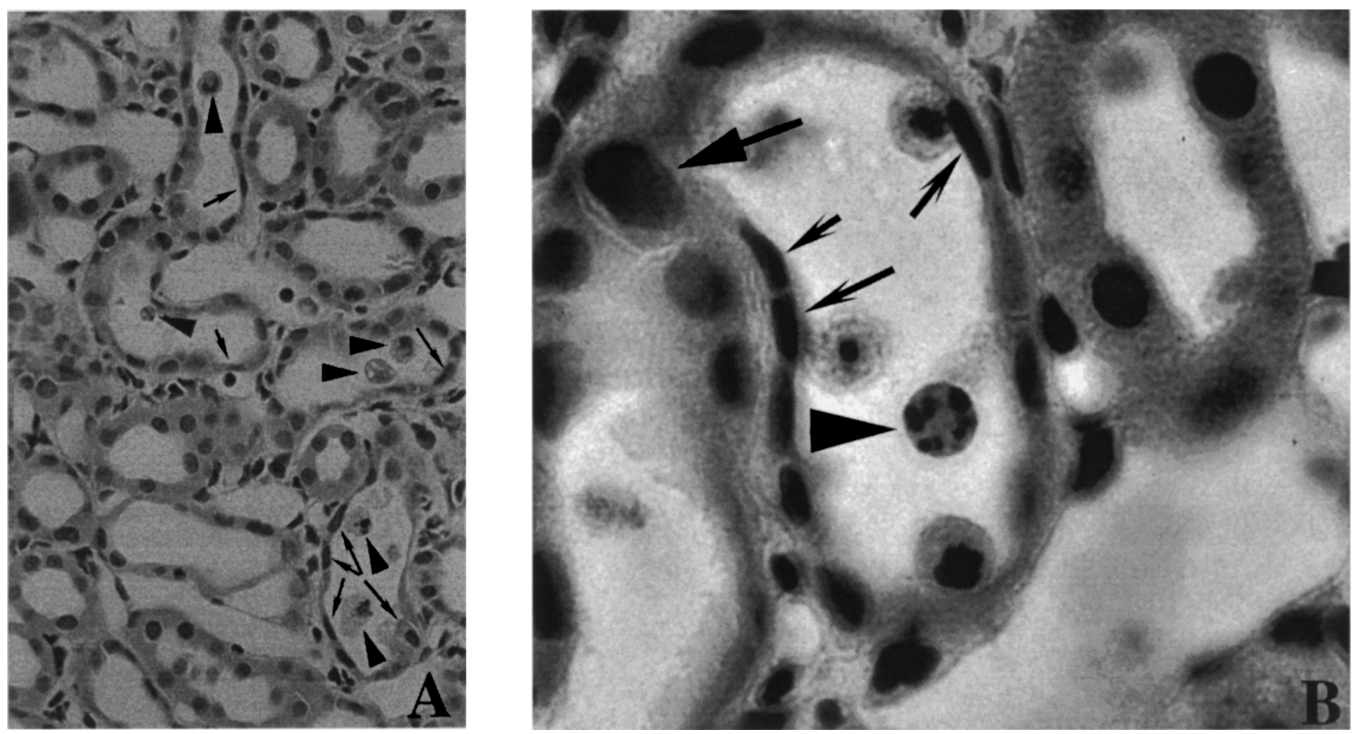

FIG. 2. (A) Hematoxylin-eosin-stained kidney section of a male rat, treated with $1 \mathrm{mg} / \mathrm{kg}$ ochratoxin A for 7 days, demonstrating a high number of necrotic $(-)$ exfoliated or regenerative $(\rightarrow)$ epithelial tubules cells in the inner part of the cortex (approx. magnification $\times 400$ ). (B) Hematoxylin-eosin-stained kidney section of a male rat, treated with $1 \mathrm{mg} / \mathrm{kg}$ ochratoxin A for 7 days, demonstrating exfoliated cells seemingly undergoing apoptotic necrosis $(\bullet)$. Regenerative epithelial cells $(\rightarrow)$ as well as cells $(\longrightarrow)$ with giant nuclei can be observed within the same affected tubule (approx. magnification $\times 800$ ). Reprinted from T. Rásonyi, J. Schlatter, and D.R. Dietrich. ${ }^{53}$

That this aspect could be significant for the understanding the obvious sex- and species-related differences and hence also for investigations into the actual mechanism of action was clearly shown by Hagelbert and Hult, ${ }^{29}$ who demonstrated OTB to have a far shorter half-life than its more toxic analog in all species tested (fish, quail, mouse, rat, and monkey). This appears to be related to a lesser affinity for plasma proteins, allowing more rapid elimination (discussed later).

\section{Serum Levels}

Unfortunately, relatively few studies carried out to determine the pathological effects of OTA in a range of experimental species have assessed the concentration of OTA present in the serum/blood of the animals at termination of the experiment. Stoev and coworkers ${ }^{51}$ analyzed the serum and renal tissue concentrations of OTA in pigs from farms in endemic areas of Bulgaria. An average of $1.32 \pm 1.25 \mathrm{ng} / \mathrm{g}$ was found in renal tissue, and serum concentrations varied considerably between 27 and $249 \mathrm{ng} / \mathrm{ml}(66.8-616 \mathrm{nM})$. A similar study carried out by Curtui and colleagues ${ }^{61}$ in Romanian slaughter pigs determined an average serum OTA concentration of $2.43 \mathrm{ng} / \mathrm{ml}(6 \mathrm{nM})$, although individual animals presented with concentrations of $13.4 \mathrm{ng} / \mathrm{ml}(33 \mathrm{n} M)$. A more recent study by Stoev et al. ${ }^{62}$ demonstrated that the feeding of experimentally highly contaminated fodder to pigs over a 6-month period resulted in serum OTA concentrations of up to $1582 \pm 40 \mathrm{ng} / \mathrm{ml}(3.9 \pm 0.1 \mu \mathrm{M})$. As these latter results arose under conditions of artificially contaminated fodder, those results showing nanomolar levels of OTA are probably more representative of actual serum concentrations.

Attempts to determine a clear link between BEN/UT and OTA have thus far concentrated on the analysis of the toxin concentration in endemic and nonendemic areas, as well as in affected and nonaffected cohorts in endemic areas. The values determined vary hugely both in healthy individuals and in BEN/UTaffected patients. This variation has been suggested to be due to several factors, including socioeconomic and/or ethnic- or tradition-based dietary considerations. ${ }^{60}$ Several reports have indicated concentrations in the low nanomolar region in the serum of BEN patients. ${ }^{63,64}$ However, one study has reported remarkably high concentrations of $0.11 \pm 0.04 \mu M$ in chronic interstitial nephropathy (CIN) patients in Tunisia. ${ }^{65}$ This disease state appears to be highly similar if not identical to BEN. The observed concentrations for healthy individuals either within or outside endemic regions has been shown to be below $1 \mathrm{n} M,{ }^{64,65}$ and Abid and coworkers reported OTA concentrations to be 16to 36-fold higher in CIN patients than in healthy individuals in their study carried out in Morocco. Peraica et al ${ }^{66}$ reported individual serum OTA levels of up to $39.4 \mathrm{n} M$ in a general survey of the population of Croatia. Unfortunately, no correlation either to the renal status of the donors or to their origins (endemic/nonendemic regions) was attempted in this study. In contrast, Nikolov and coworkers ${ }^{67}$ demonstrated concentrations of $\geq 15 \mathrm{ng} / \mathrm{L}$ to correlate well with the incidence of UT and BEN in endemic areas. Healthy control cohorts showed OTA concentrations below this value. Although some studies have 
attempted to correlate serum OTA concentration with the concentrations detected in locally produced foodstuffs and/or with a causal role in renal disease, ${ }^{65,67}$ no comprehensive study has been carried out that controlled for possible confounding factors such as alcohol/medication consumption and smoking. Any future epidemiological studies aimed at defining the role of OTA in BEN and UT must take such considerations into account.

\section{Protein Binding and Kinetics}

Protein binding is probably the decisive factor in determining the half-life of OTA in any given species and hence the susceptibility of that species to renal damage. Several studies have determined OTA to have an extremely high affinity for serum albumin and other macromolecules in the blood. ${ }^{30,68,69}$ This bond with serum albumin has been suggested to result in the generation of a mobile reservoir of ochratoxin, which can be slowly released and hence rendered bioavailable over extended periods of time and furthermore, retard the elimination of OTA from the body. Support for this thesis was presented by Kumagai and coworkers, who demonstrated the half-life of OTA to be much shorter in albumin-deficient than in normal rats. ${ }^{70}$ Moreover, these authors also demonstrated 20- to 70-fold higher concentrations of OTA in the bile and urine of albumin deficient rats than in the control cohort. These observations demonstrate the importance of serum/protein binding for the biological half-life of ochratoxins and arguably also the importance of this characteristic for the interpretation of experimental data on the mechanism of action, both in vivo and in vitro.

Although a complete review of the kinetics of OTA is beyond the scope and intention of this text, the salient points are outlined here. More detailed reviews carried out by Marquardt et al. ${ }^{39}$ and the Joint Expert Committee on Food Additives ${ }^{35}$ and authors cited therein are recommended to the reader. OTA has been determined to be absorbed rapidly both from the stomach and the small intestine in rats and mice. Indeed, absorption from the jejunum can take place even against a concentration gradient, ${ }^{71}$ suggesting the presence of organic anion transporters with the capacity to transport OTA (discussed later). Following absorption, the concentration of the toxin and its metabolites depends on a number of factors including dose, route of administration, the duration of administration, and also on species-specific factors such as half-life and the degree of serum binding. ${ }^{29,72}$ Enterohepatic circulation also appears to be a factor in the kinetics of OTA. Sreemannarayana and coworkers ${ }^{73}$ observed a single protracted secondary peak in their analysis of serum OTA concentrations in calves following oral OTA administration and suggested this to be due to a superimposition of biliary OTA recycling on the overall elimination process. Similar observations have been made by other authors in rats and mice. ${ }^{58,74,75}$ The reabsorption of OTA by the kidney has also been proposed to facilitate the residual persistence of the toxin and hence the renal toxicity in rodents. ${ }^{76,77}$ In vivo metabolism of OTA in a number of species including rodents ${ }^{78}$ and ruminants ${ }^{79}$ has been shown to predominantly yield the nontoxic congener ochratoxin- $\alpha$, that is, the isocumarin moiety lacking the phenylalanine group (Figure 1). This metabolic peptide bond cleavage appears to be a function of the intestinal tract, as little conversion of the parent compound has been observed in either kidney or liver. ${ }^{33,80}$ Other detected metabolites include the $R$ and $S$ epimers of 4-hydroxy-OTA. The prevalence of each of these epimers appears to be species-dependent, with for example $4 R-\mathrm{OH}$ predominating in human and rat microsomal systems ${ }^{78}$ and the $4 S$-OH variant being more commonly produced by pig liver microsomes. Størmer et al. also reported rabbit microsomes to produce 10-hydroxy-OTA. Both biliary and renal routes are involved in the excretion of OTA by rats and mice, with the biliary route predominating, although this may also be dependent on the dose and the route of administration. ${ }^{27,72,81,82}$ In contrast, in humans and nonhuman primates (vervet monkeys), predominantly parent compound is excreted and the primary route of excretion is via the kidney. ${ }^{60,83}$

\section{Transport Proteins}

The blatant differences in the relative sensitivities of various species to ochratoxin have been suggested to be governed by specific renal handling of OTA. For example, variations in the transporter and/or binding protein complements of renal cells from different species could play a role in determining OTA accumulation in sensitive cells. Indeed, the findings of Vedani and Bruinink ${ }^{84}$ that OTA binds 27 -fold more strongly to a modelled pseudoreceptor than OTB could help to explain variations in half-lives and toxicity. Heussner and colleagues ${ }^{85}$ have also reported stark species-dependent differences in the binding characteristics of OTA to proteins present in renal cortical homogenates from pig, mouse, rat, and human of both sexes. Using a modification of a classical receptor-binding assay, these authors described the presence of at least one homogeneous OTA-binding component. This component appeared to have low affinity but high capacity for ${ }^{3} \mathrm{H}$-OTA, which could be competed for by a range of substances known to have affinity for steroid receptors and/or for various organic anion transporters previously reported to be responsible for the transport of OTA. ${ }^{86}$ Based on the pattern of protein binding competition, the authors suggested that this binding component does not belong to the organic anionic transporters (discussed later) previously described. The generated binding-capacity ranking of human $>$ rat $>$ pig $\geq$ mouse correlates well with the biological half-lives determined by other authors (human $>$ rat $\geq$ pig $>$ mouse) and also with the toxicity ranking for experimental animals in vivo. Il'ichev and coworkers ${ }^{87}$ described high-affinity binding of OTA dianions to human serum albumin (HSA). Using recombinant fractions of HSA, the authors concluded that HSA has at least two unique binding sites, each of which can accommodate one dianion. The highest affinity binding site was determined to be subdomain IIA of HSA; however, subdomain IIB and domain I were determined to be critical for the integrity of this binding site. Interestingly, aspartame could not displace OTA from these binding sites. The combination of the results observed by these 
investigators (Vedani and Bruinink, Heussner et al, and Il'ichev et al.) could suggest an even higher sensitivity for humans toward OTA-mediated toxicity than previously acknowledged.

Other authors have also indicated OTA to be a substrate for the family of organic anion transporter proteins (Oatp). The best characterized of these is the OAT1 family, made up of four splice variants from the same gene (OAT1-1, -2, -3, -4$){ }^{88}$ This transporter family, initially demonstrated in liver, has an extremely wide substrate specificity, and individual members have since been found in numerous other organ systems, including kidney and brain. Other members of the transporter family include the Oats, which are the rodent equivalents of the human proteins, which are designated with uppercase letters. The nomenclature of these proteins, with some authors denoting human variants with a lowercase $h$ prefix, is complicated; however, the change to the use of standardized gene symbols denoting species and gene locus currently in progress should simplify matters. A summary of the transporter proteins thought to be involved in OTA accumulation, together with their approved gene symbols, is given in Table 2, and a schematic model of their function is outlined in Figure 3. Excellent detailed reviews of the organic anion transporters are available,$^{88,89}$ and further information on nomenclature can be obtained from the Internet pages of the Human Gene Nomenclature Committee (HUGO) (http:// www.gene.ucl.ac.uk/nomenclature) and the Rat Genome and Nomenclature Committee (RGNC) (http://rgnc.gen.gu.se).

Controversy exists as to whether OTA is transported solely by the PAH transport pathway as suggested by Skol et al. ${ }^{90}$ and Gekle and coworkers, ${ }^{91}$ working in rabbit renal-basolateral membrane vesicles and opossum kidney cells, respectively, or if, as reported by Groves and colleagues ${ }^{92}$ in rabbit renal proximal tubules, accumulation occurs via a combination of passive diffusion and/or nonspecific binding and carrier-mediated processes. Whichever is the case, cellular accumulation probably

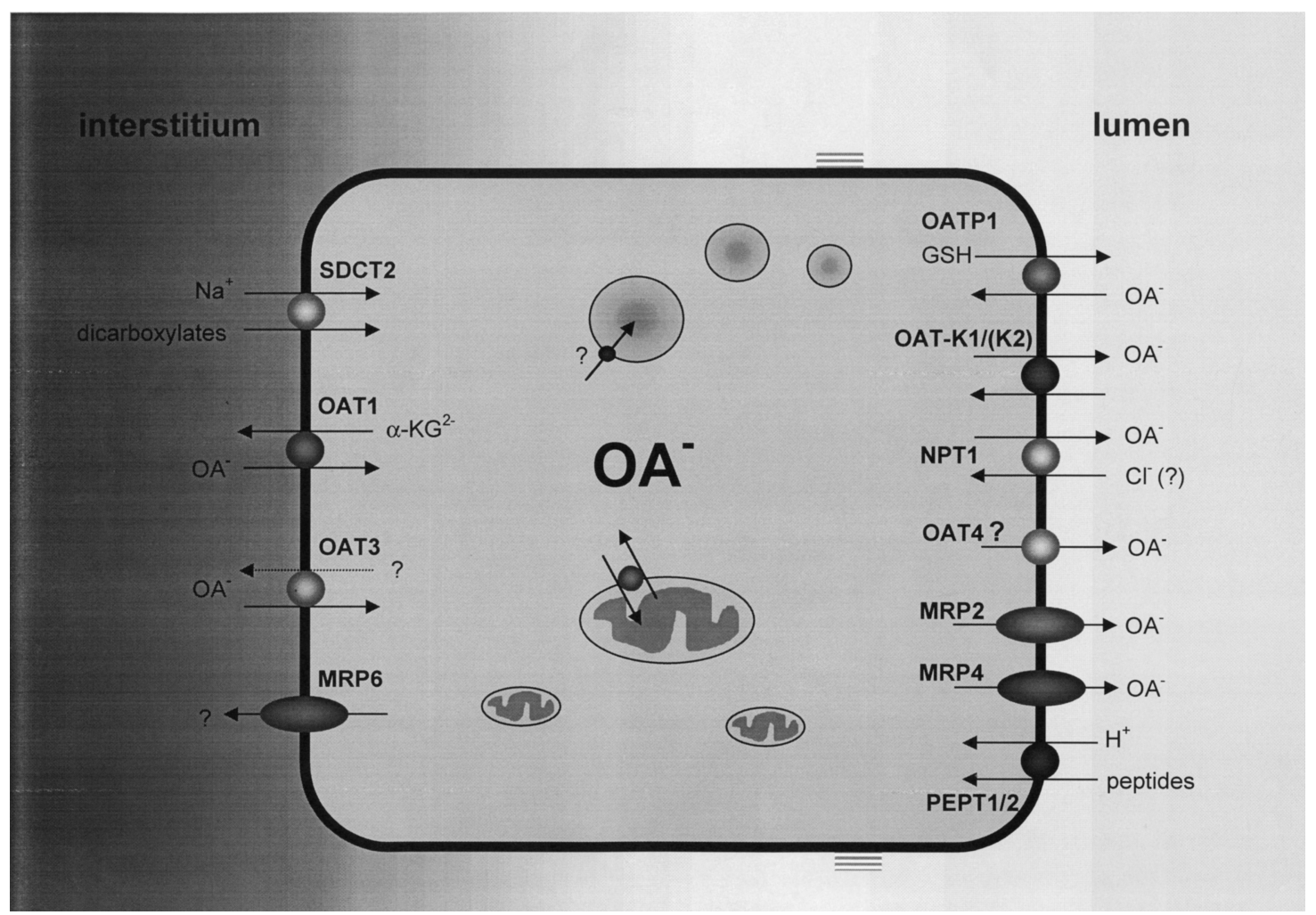

FIG. 3. Schematic model of organic anion transporters in kidney proximal tubule. Uptake of organic anions $\left(\mathrm{OA}^{-}\right)$across the basolateral membrane is mediated by the classic $\mathrm{Na}^{+}$-dependent organic anion transport system, which includes $\alpha$-ketoglutarate $\left(\alpha-\mathrm{KG}^{-}\right) / \mathrm{OA}^{-}$exchange via the organic anion transporter, OAT1, and $\mathrm{Na}^{+}$-ketoglutarate transport via the $\mathrm{Na}^{+} /$dicarboxylate co-transporter (SDCT2). A second $\mathrm{Na}^{+}$-independent uptake system for bulky $\mathrm{OA}^{-}$has been identified, but its molecular identity and driving force are unknown. OAT3 may be a possible candidate. The role of the multidrug resistance transporter, MRP6, as putative ATP-dependent extrusion mechanism to the interstitium, is still unclear. The apical (luminal) membrane contains various transport systems for efflux of $\mathrm{OA}^{-}$into the lumen. The multidrug resistance proteins MRP2 and MRP4 mediate primary active transport. The organic anion-transporting polypeptide OATP1, the kidney specific OAT-K1, and the supposed isoforms OAT-K2 and Oat4 may mediate facilitated $\mathrm{OA}^{-}$efflux, but they could also be involved in reabsorption of peptidelike drugs. From Russel and coworkers, ${ }^{88}$ with permission. 


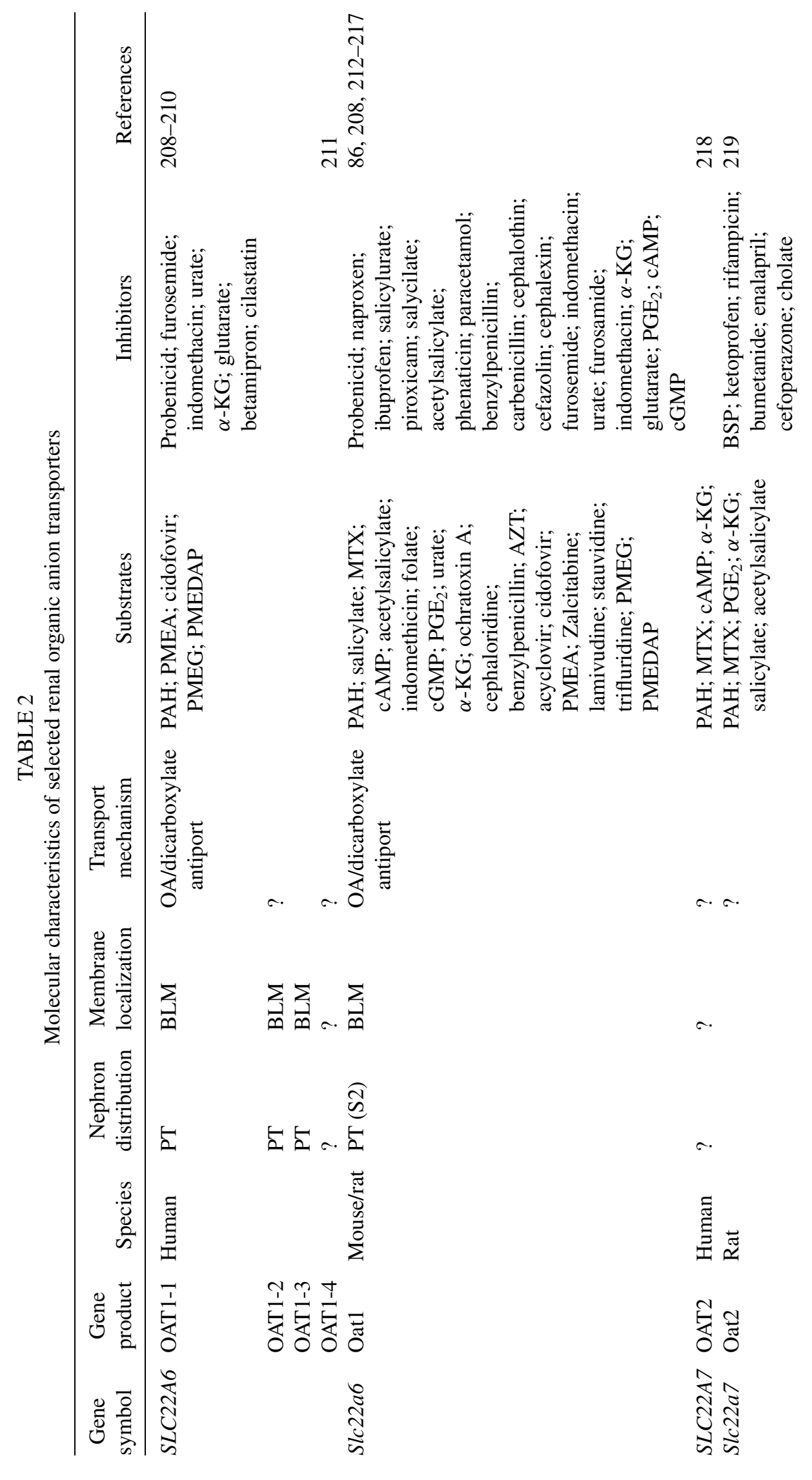




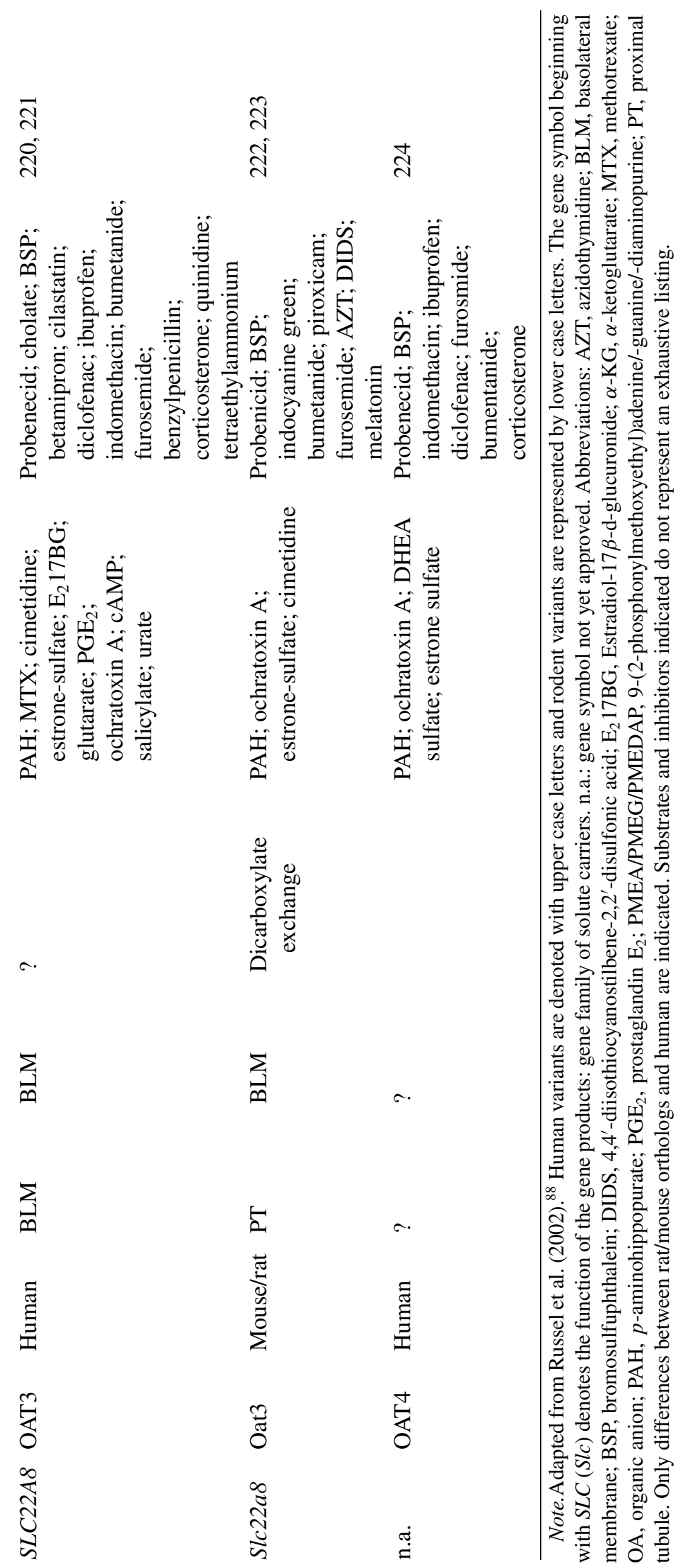


plays an important role in OTA-mediated cytotoxicity. O'Brien and colleagues ${ }^{93}$ demonstrated primary renal epithelial cells of human and porcine origin to rapidly accumulate 10 - to 15 -fold more ${ }^{3} \mathrm{H}$-OTA than their continuous cell line counterparts. Intracellular accumulation of OTA has been confirmed by other researchers and demonstrated to occur extremely rapidly, with a plateau phase occurring within one to two minutes of OTA addition to cultures of renal cells from mice expressing the multispecific human organic anion transporters hOAT1 (OAT1, SLC22A6) and hOAT3 (OAT3, SLC22A8) ${ }^{94}$ and in mouse proximal tubule cells stably transfected with hOAT4 ${ }^{95}$ Moreover, a recent study by Buist and Klaassen ${ }^{96}$ demonstrated large sexand species-dependent variations in the expression levels of a number of organic anion transporters. In this study, sex-specific differences in mRNA expression levels were observed for Oat2 (Slc22a7) and Oat3 (Slc22a8) but not for Oat1 (Slc22a6). These results correspond to those obtained in a similar study carried out by the same authors in rats. ${ }^{97}$ The authors also demonstrated the expression levels of some members of this protein family to be age dependent. If intracellular OTA accumulation and/or excretion is indeed a function of the organic anion transport system, then a closer analysis of these proteins including expression levels and species and substrate specificity could help generate a more reliable risk assessment for OTA and, furthermore, could help determine strategies for the prevention and treatment of intoxications.

\section{HOW DOES OTA MEDIATE ITS EFFECTS?}

The molecular mechanism by which OTA actually mediates cell death and/or antiproliferative effects is still a matter of controversy, not least because of the numerous endpoints, cell systems, experimental conditions, and concentration ranges employed by the various research groups. In a study that tested primary human and porcine renal epithelial cells as well as continuous epithelial cell lines from rat (NRK-52E) and pig (LLC-PK1), O'Brien et al. ${ }^{93}$ demonstrated primary cells of human origin to be the cell type most sensitive to the antiproliferative/cytotoxic effects of OTA, with a slight tendency for an even higher sensitivity of cells from female donors (significant reduction in cell numbers was apparent after 48 hour exposure to $1 \mathrm{n} M$ OTA). This study also reported an approximately ten-fold weaker effect of OTB. Interestingly, approximately $15 \%$ of each cell type survived exposure to even extremely high $(\geq 100 \mu M)$ concentrations of OTA over extended time periods (up to $96 \mathrm{~h}$ ) and could be demonstrated to reenter the cell cycle and proliferate following removal of the toxin. ${ }^{93,98}$ These observations raise the question of the existence of an OTA-resistant, possibly apoptotic-defective, subpopulation of cells. In the same study, the NRK-49F renal fibroblast cell line was shown to be relatively insensitive to the antiproliferative/cytotoxic effects of OTA despite accumulating OTA concentrations comparable with their epithelial counterparts, NRK-52E. Similar observations of OTA resistance have been made for primary human fibroblasts
(O'Brien, personal communication). This indicates that the progressive fibrosis characteristic for BEN could arise through a cytotoxic/cytostatic effect of OTA in renal epithelial cells, coupled with continued fibroblast proliferation, resulting in progressive replacement of healthy, functional tissue with fibroblasts. This model proposed by O'Brien and coworkers is illustrated in Figure 4.

OTA and/or its metabolites have been reported to be both mutagenic ${ }^{99}$ and nonmutagenic $c^{4,72,100}$ in a range of microbial testing systems, although the accepted failings of microbial testing systems for mammalian toxicity testing should not be forgotten here. Several other potential mechanisms including sister chromatid exchange (SCE) ${ }^{101}$ unscheduled DNA synthesis, ${ }^{102}$ the generation of reactive oxygen species, ${ }^{103}$ and the induction of apoptosis in sensitive cell populations ${ }^{104,105}$ have been proposed.

\section{Is OTA (or One of Its Metabolites) Genotoxic?}

Föllmann and coworkers reported a dose-dependent increase in SCE in cultured porcine urinary bladder cells exposed to OTA at concentrations ranging between $100 \mathrm{p} M$ and $100 \mathrm{n} M .{ }^{101} \mathrm{How}-$ ever, this study was carried out in serum-deprived cells, which, considering the known affinity of OTA for serum proteins already described, is questionable. Similar results were obtained by Degen and co-workers ${ }^{106}$ and by Dopp et al. ${ }^{107}$ in ovine seminal vesicles and Syrian hamster embryos, respectively. In contrast, Cooray and coworkers ${ }^{108}$ reported a lack of SCE in human lymphocytes following exposure to 10-25 $\mu M$ OTA. Furthermore, concentrations ranging between $60 \mathrm{p} M$ and $1 \mathrm{~m} M$ could not induce unscheduled DNA synthesis in primary hepatocytes nor SCE in ovary cells from Chinese hamsters, which had been treated with OTA in vivo. ${ }^{109}$ The ability of OTA to induce an increase in micronucleus frequency was investigated by Donmez-Altuntas and coworkers. ${ }^{110}$ These authors reported OTA, at concentrations ranging from $100 \mathrm{p} M$ to $10 \mu M$, to have no effect on the frequency of micronuclei in cultures of primary human lymphocytes. An increase in micronucleus frequency and a decrease in the number of binucleated cells were apparent, however, following exposure to the extremely high concentration of $25 \mu M$. This coincident reduction in binucleated cells is indicative of cytotoxicity rather than a specific genotoxic action of OTA. Moreover, $25 \mu M$ OTA has been demonstrated to be acutely cytotoxic in the absence of serum in a number of cell models by several researchers.

Further important considerations in mode-of-action determination, particularly with respect to carcinogenic substances, are relevant concentrations, exposure regimens, and model systems. Inappropriate choice of any of the aforementioned can yield results that may not represent the "real-life" situation. Ehrlich and coworkers reported a dose- and time-dependent increase in the percentage of mononuclear cells in cultures of the humanderived cell line HepG2 following exposure to OTA for periods ranging from 1 to 24 h. ${ }^{111}$ The authors stressed, however, that these results were obtained using concentrations of OTA that 


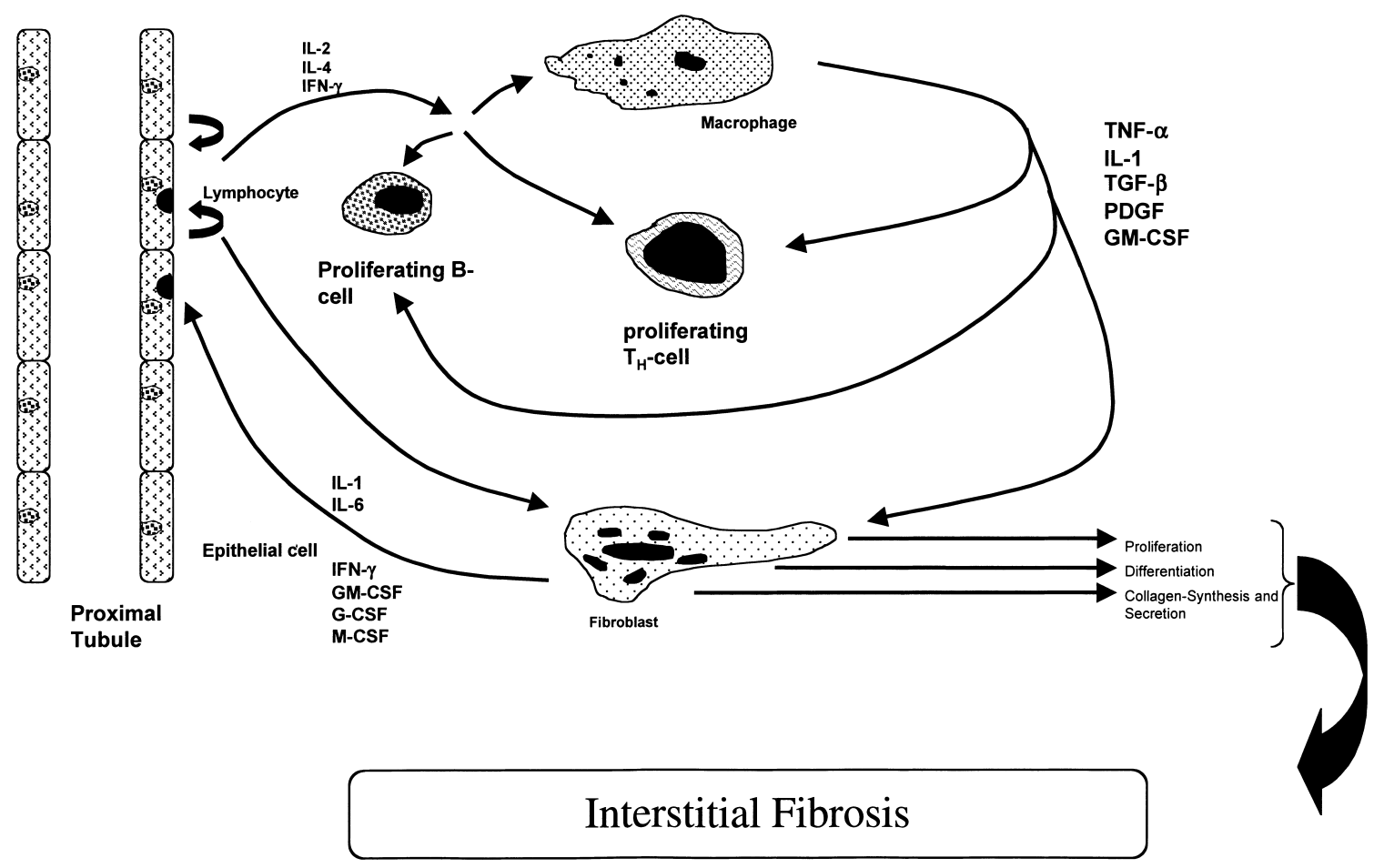

FIG. 4. Proposed model for OTA-mediated fibrosis. The death of epithelial cells, which are more sensitive to OTA-mediated cytotoxicity, allows or indeed may stimulate the proliferation of fibroblasts, which are relatively OTA-insensitive. Cell death and the resulting debris leads to the recruitment of macrophages and other activated cells of the immune system. The ensuing release of cytokines exacerbates the situation, resulting in a chronic, self-perpetuating fibrosis. Abbreviations: GM-CSF, granulocytemacrophage colony-stimulating factor; IFN, interferon; IL, interleukin; PDGF, platelet-derived growth factor; TGF, transforming growth factor; TNF, tumor necrosis factor.

were 50- to 100 -fold higher $(5-50 \mu \mathrm{g} / \mathrm{ml})$ than those that have been found in human serum to date. ${ }^{112,113}$ As an increased incidence of mononuclear cells can result from either chromosome breakage or spindle disruption, these authors suggested OTA to have a mixed (epigenetic and genotoxic) mode of action. It was furthermore suggested that these experiments should be repeated under more "realistic exposure concentrations."

Gross-Steinmeyer and coworkers, working in the nanomolar to micromolar range, found no evidence of reactivity between ${ }^{3} \mathrm{H}$-OTA and the DNA of either rat or human primary hepatocytes, ${ }^{114}$ although primary cells are normally more susceptible to toxic insult than their transformed continuous cell line counterparts. This group also reported ${ }^{3} \mathrm{H}$-OTA to be very poorly metabolized by primary hepatocytes. Three OTA metabolites that had previously been reported to be produced by rat microsomes were generated by primary rat hepatocytes in this study, and six metabolites were determined in the supernatant of human hepatocytes following eight-hours incubation. None of these metabolites could be demonstrated to react with DNA and, indeed, represented only 3-6\% of the total OTA added. Similarly, Zepnik and coworkers ${ }^{115}$ reported low metabolism rates in liver microsomes from rats and mice, in human cytochrome P-450 (3A4, 1A2 and 2C9 Supersomes), and in rat and human
S9 fractions fortified with NADPH and glutathione, semipurified glutathione $S$-transferase, horseradish peroxidase, and soyabean peroxidase. ${ }^{115}$ These authors concluded that the oxidative biotransformation of OTA occurs at extremely low rates and is unlikely to result in the production of highly reactive intermediates, and those intermediates that are formed are unlikely to be capable of binding to DNA. Likewise, Gautier and coworkers described extremely low metabolism rates when OTA was incubated with a range of human and rat enzyme systems. ${ }^{116}$ Thus, the latter studies lend further support to the assumption that the toxicity of OTA is mediated by the parent compound and not by one of its metabolites.

The generation of DNA adducts by reactive metabolites and by the parent compound has been reported in several studies employing the ${ }^{32} \mathrm{P}$-postlabelling method carried out in mice ${ }^{117-119}$ and rats. ${ }^{120}$ Castegnaro and colleagues determined the levels of DNA adducts in male rats to be higher than that in females. This was suggestive of a correlation between the incidence of DNA adducts and the known sex-dependent carcinogenicity of OTA in rats. However, no correlation can be drawn between the incidence of DNA adducts and the observed frequency of adenocarcinoma or karyomegaly in this species. Indeed although approximately $42 \%$ of female rats presented with DNA adducts, some 
of which were at the same levels as in exposed male rats, neither karyomegaly nor renal epithelial tumors were evident. ObrechtPflumio and Dirheimer ${ }^{121}$ also reported the generation of both DNA and deoxyguanosine 3 -monophosphate adducts in salmon testes DNA following exposure to OTA that had been previously incubated with mouse microsomes. Using the identical ${ }^{32} \mathrm{P}$-postlabeling method used by the Creppy, Pfohl-Leszkowicz, and Castegnaro research groups, these authors found the incidence and number of spots to be much higher than that previously reported for Lewis, Sprague-Dawley, and dark Agouti (DA) rats. This contrasts sharply with the known relative in vivo sensitivities of mice and rats for OTA-mediated carcinogenicity. Furthermore, the lack of DNA reactivity of ${ }^{3} \mathrm{H}$-OTA or its metabolites reported by Gautier et al. ${ }^{116}$ and by GrossSteinmeyer and colleagues ${ }^{114}$ is not indicative of OTA-DNA adduct formation. As the ${ }^{32} \mathrm{P}$-postlabeling method cannot distinguish between adducts caused by the chemical itself and those caused by the products of oxidative stress and cytotoxicity, the validity of using the ${ }^{32} \mathrm{P}$-postlabeling method for determining DNA adducts and, moreover, the interpretation of results obtained using this method as representing a purely genotoxic mechanism of action must be questioned. Furthermore, neither the presence of oxidative changes, nor the reported DNA adducts could be corroborated using HPLC-MS or LC-MS. ${ }^{115,116,122}$

Dai and coworkers ${ }^{123}$ recently reported that OTA can indeed react with DNA via a phenolic radical, and have synthesized and characterized the resulting C8-deoxyguanosine (dG) adduct. The same group previously described the formation of a quinone species resulting from the dechlorination of OTA. ${ }^{124,125}$ This quinone species could potentially undergo redox cycling and cause oxidative stress and/or form $\mathrm{dG}$ adducts. These authors suggested that OTA can thus cause the formation of reactive oxygen species, resulting in oxidative DNA damage and the production of 8-oxoG DNA adducts. The authors qualified this, however, with the remark that the quinone derivative is only formed at relatively low levels under physiological conditions. In the same study, the quinone species was reported to form a conjugation product with glutathione. Indeed, the reduction in primary rat and human hepatocyte glutathione levels following exposure to OTA reported by Gross-Steinmeyer and coworkers, ${ }^{114}$ provides some circumstantial evidence for the theory of OTA-mediated radical formation. The reader is directed to the cited studies for a detailed scheme of the suggested sequence of events. These results, while certainly indicating a potential for the generation of deoxyguanosine, remain to be confirmed as occurring either in vivo or in vitro.

It should also not be forgotten that the marked sex- and species-differences associated with OTA toxicity do not speak for a purely genotoxic mechanism. More likely is the predominance of an epigenetic pathway. Several potential epigenetic pathways have been proposed. Curiously, some of these, such as the inhibition of t-RNA synthetase, have been suggested by the same groups that also reported OTA to exert its effects by means of a directly genotoxic mechanism. Creppy and cowork- ers reported an inhibition of t-RNA synthase by OTA and its metabolites in cultured hepatoma cells ${ }^{126}$ and in yeast, ${ }^{127}$ which could be reversed by addition of phenylalanine to the culture medium. Enhancement of NADPH or ascorbate-dependent lipid peroxidation $^{103,128,129}$ and cytoskeletal changes ${ }^{130}$ have also been promoted as the initial event in OTA-mediated cytotoxicity. Most of these reports have, however, arisen from studies employing extremely high concentrations of OTA that are probably irrelevant for the in vivo situation and are in fact close to the acutely lethal dose in rats and mice.

\section{Is OTA Pro-Apoptotic or Pro-Cytotoxic?: A Role for Oxidative Stress and Free Radicals}

Cell death can be categorized as either necrotic or apoptotic, and which process predominates is dependent on many factors, including the substance and experimental system investigated and in no small way on the dose/concentration employed. Although cell membrane damage is characteristic for necrosis, apoptosis may be induced by a number of events, including oxidative stress, free radicals, cytokines, and growth factors. Indeed several reports, both in vivo and in vitro, have indicated OTA to induce oxidative stress, which may then lead either to subsequent DNA damage or to the initiation of apoptotic processes. Petrik and colleagues ${ }^{131}$ recently published a study in which apoptotic cells in the kidneys of rats exposed to the low dose of $120 \mu \mathrm{g}$ OTA/kg body weight for up to 60 days were detected using the TUNEL assay. This apoptosis was accompanied by increased malondialdehyde formation, an increase in lipid peroxidase (LPO) concentration, and reduced superoxide dismutase (SOD) activity, all of which are indicative of oxidative stress. All of these effects were found to be dose and time dependent but were not associated with an impairment of renal function. This probably indicates that the effects observed play a role in the very early stages of OTA-mediated renal toxicity. A similar OTA-mediated (500 $\mathrm{n} M$ OTA) increase in lipid peroxidation, as measured by increased malondialdehyde formation, has also been reported ${ }^{132}$ in a reconstituted system consisting of microsomal phospholipid, NADPH-cytochrome P450 reductase, and iron ions. These authors suggested a mechanism by which lipid peroxidation is facilitated by OTA chelation of $\mathrm{Fe}^{3+}$ with subsequent reduction to $\mathrm{Fe}^{2+}$. Meki and Hussein ${ }^{133}$ also demonstrated an increased production of lipid peroxidation products and malondialdehyde formation, coupled with a decrease in the levels of several enzymes involved in free-radical scavenging (SOD, GSH, GSPx, and GR) in the serum, liver, and kidneys of rats treated with OTA ( $250 \mu \mathrm{g} / \mathrm{kg} /$ day, 4 weeks). These effects could be prevented by coadministration of melatonin, supporting a role of oxidative stress in the process. In contrast, Gautier and coworkers ${ }^{122}$ found no increase in either malondialdehyde concentration or the formation of 8-oxo-7,8dihydro- 2 -deoxyguanosine in the kidneys of rats $24 \mathrm{~h}$ following oral dosing with up to $2 \mathrm{mg} / \mathrm{kg}$ OTA. However, a $22 \%$ decrease in plasma $\alpha$-tocopherol levels and a fivefold increase in renal 
hemoxygenase-1 activity, both of which are markers of oxidative stress, were apparent. The differences in the in vivo studies mentioned can probably be explained by the different dosage regimens employed. Nevertheless, all of the studies cited provide evidence for the involvement of ROS and free radicals in general.

Further support for the involvement of oxidative stress and/or free radical generation can be found in the in vitro observations of Schaaf and co-workers, ${ }^{134}$ who reported OTA to cause an increase in the production of ROS, a depletion of intracellular GSH, and the production of 8-oxyguanine in LLC-PK1 and primary rat proximal tubule cells. Interestingly, the increase in ROS occurred before any loss in cell viability became apparent, indicating the former to be a cause rather than a consequence of cytotoxicity. Furthermore, the effects could be blocked by preincubation with the antioxidant $N$-acetylcysteine, which prevented any loss of cell viability, but not with $\alpha$-tocopherol, indicating a role for several different species of reactive oxygen species. In contrast, Hoehler et al. ${ }^{135}$ demonstrated vitamin $\mathrm{E}$ but not vitamin $\mathrm{C}$ to ameliorate the prooxidative effects of OTA in the chick model. The same group also demonstrated the generation of free radicals and malondialdehyde formation in Bacillus brevis ${ }^{136}$ and in hepatocytes ${ }^{137}$ following exposure to OTA and several of its analogs. Interestingly, the impact of OTB on free radical production in the B. brevis system was far less than that observed for OTA, which correlates with their relative in vivo and in vitro potencies. These effects could be ameliorated by the inclusion of vitamin $E$ in the incubation mixture. Indeed, antioxidants have been reported by several groups to reduce OTA renal, neural, and hepatotoxicity both in vivo and in vitro, ${ }^{138-140}$ underlining the need for further investigation.

The generation of free radicals could naturally also have an impact on cellular mitochondrial respiration. Indeed, such effects on isolated mitochondria have been reported by several investigators, ${ }^{137,141-145}$ although at very high OTA concentrations. Conversely, a disruption of normal mitochondrial function could result in the production of free radicals, resulting in direct damage to DNA and/or apoptosis as outlined earlier. The sequence of events can only be determined by carefully planned and executed experimental procedures, which take into consideration concentration and presence/absence of serum. Luhe and colleagues ${ }^{146}$ recently reported the first step in the process of linking these various observations in their recent study of treatment-specific transcriptional changes in rat kidney in vivo and in renal proximal tubule cells in vitro. Using the technique of DNA arrays, these authors determined OTA to alter the transcription levels of several genes known to be involved in the response to DNA damage and apoptosis (GADD 153, GADD 45, and annexin V) to oxidative stress (hypoxia-inducible factor 1, catalase) and inflammatory reactions (alpha-2-macroglobulin, ceruloplasmin, cathepsin S). The changes in gene expression were similar in vitro and in vivo, indicating that the in vitro model system used may indeed adequately represent the in vivo situation, and the pathological changes observed in vivo correlated with those of other authors using comparable dosage regimens. As, however, very high concentrations of OTA were also employed in this study (both in vivo and in vitro parts), a long-term, low-dose study investigating the same or similar parameters would perhaps refine the information gained.

Recently, several reports have been published on OTAmediated cytotoxicity at dietary-relevant (nM) concentrations. Gekle et al., ${ }^{147}$ Schwerdt et al., ${ }^{104}$ and Horvath et al. ${ }^{105}$ demonstrated OTA to induce apoptosis in dedifferentiated MDCK-C7 cells, immortalized human kidney (IHKE) cells, and human kidney epithelial (SB3) cells. Schwerdt and coworkers observed a slight but significant increase in the activity of the pro-apoptotic caspase 3 in IHKE cells following exposure to $10 \mathrm{n} M$ OTA, which could not be abrogated by the use of radical scavengers or intracellular calcium chelators. Exposure to higher concentrations resulted in DNA fragmentation and chromatin condensation. Studies by Gennari and coworkers ${ }^{148}$ and Assaf and colleagues ${ }^{149}$ recently reported the induction of apoptosis in LLC-PK1 and human peripheral blood mononuclear cells, respectively. Following exposure to OTA concentrations between $5 \mu M$ and $50 \mu M$ in serum-free medium, similar results were obtained by Gekle and colleagues, ${ }^{147}$ who in addition showed OTA to potentiate the pro-apoptotic action of tumor necrosis factor- $\alpha$ in MDCK-C7 and opossum kidney cells. Care should however be taken in the interpretation of these results, as the studies have been carried out either in previously transformed cells, in cells that had been synchronized via pretreatment with hydroxyurea, or in the absence of fetal calf serum in the culture medium. Transformed cells are known to respond to toxic insults in a different manner than their nontransformed counterparts, and synchronization in the G1 phase of the cell cycle with hydroxyurea suppresses the entire protein-synthetic machinery of the cell. Finally, the absence of serum is known to have an enormous effect on the type of response mounted by a cell to a given toxin, particularly when the toxin in question possesses protein-binding potential.

In contrast, a study carried out by Seegers and coworkers ${ }^{150}$ reported that OTA exposure only induced apoptosis in 5\% of hamster kidney cells in vitro. Other authors, working with serum-replete medium, found no evidence for the induction of apoptosis in either LLC-PK1 or NRK-52E cells (Kristin Kobras, personal communication), nor in human or porcine primary renal epithelia exposed to OTA at concentrations ranging from $1 \mathrm{n} M$ to $25 \mu M .^{98,151}$ Cytotoxic effects could, however, be demonstrated in primary human kidney cells exposed to dietary-relevant concentrations of OTA in serum-replete medium using the standard methods of analysis of MTT reduction, neutral red uptake, and counting of intact nuclei stained with crystal violet. ${ }^{93,152}$ Interestingly, a large number of cells floating in the culture medium following OTA exposure demonstrated the ability to reattach to the substrate and reenter the cell cycle if collected and returned to OTA-free, serum-replete medium. It is thus possible that these cells could be resistant to OTA-mediated cytotoxicity and/or 
apoptosis, if indeed apoptosis occurs at such low concentrations, and could represent the in vitro equivalent of OTA-resistant cells in vivo. Such cells could form the basis for tumor generation via transformation and invasion into the transitional epithelium. This theory is supported by the in vivo findings of Rásonyi and colleagues, ${ }^{153}$ who found apparently apoptotic cells in the lumen of affected tubules in rats (see Figure 2) following OTA exposure and suggested apoptosis to be a secondary or even tertiary event in OTA toxicity, resulting from disruptions in intercellular communication and cell-basal lamina adhesion processes. This theory is also in agreement with that proposed by Horvath et al., who observed OTA to disrupt gap-junctional intercellular communication in human kidney and rat liver epithelial cells. $^{105}$

\section{Other Proposed Mechanisms}

Several other potential mechanisms have been proposed, including an increase in intracellular $\mathrm{pH}$ via a disruption in membrane anion conductance, ${ }^{154}$ inhibition of mitochondrial transport, ${ }^{141,142}$ prevention of heat-shock protein 70 induction, ${ }^{155}$ and inhibition of mitochondrial respiration. ${ }^{143}$ The role of each or any of these must be more intensively investigated, as they could well correlate with the postulated role of the organic anion transporters as outlined earlier.

\section{IMMUNOTOXICITY}

\section{In Vivo Investigations}

Reports of an increased susceptibility to infection in various species of domestic animals following exposure to OTAcontaminated fodder led to a number of early studies being carried out into this area. OTA results in a suppression of the immune system in every species tested to date. The type of immune suppression experienced appears to be dependent a number of factors, including the species involved, the route of administration, the dose tested, and, by no means least, the methods used to detect the effects (endpoints). These effects, outlined in this section, are summarized in Table 3.

Harvey and coworkers ${ }^{156}$ described a reduction in cutaneous basophil (CBH) and delayed type hypersensitivity (DTH) to phytohemaglutinin (PHA) and tuberculin protein, respectively, in pigs following OTA exposure $(2.5 \mathrm{mg} / \mathrm{kg}$ in fodder $)$. This was coupled with a reduced stimulation index for lymphoblastogenesis, reduced macrophage activity, and decreased concanavalin A-mediated interleukin (IL)-2 production. Similar results (suppression of IL-2 production and PHA-stimulated lymphoblastogenesis) were obtained by the same group in vitro using porcine lymphocytes. ${ }^{157}$ The authors concluded that OTA exposure results in a depression of cell-mediated immunity without involvement of the humoral immune system.

In a further series of experiments using weaner pigs, Müller and colleagues ${ }^{158}$ demonstrated OTA (20-50 $\mu \mathrm{g} / \mathrm{kg}$ b.w., sc) to cause an increase in total leukocyte number, to reduce relative lymphocyte counts, and to raise relative neutrophil counts. A tendency toward a reduced ability of polymorphonuclear neutrophils to phagocytose FITC-labeled Pasteurella was also apparent in this study, but was not always statistically significant. The authors suggest that this reduction in phagocytic ability could in part be explained by the observed increase in apoptotic phagocytes. A similar reduction in the phagocytic activity of natural- and T-killer cells was demonstrated in pigs by Harvey et al. ${ }^{156}$ In contrast to the results obtained by Holmberg and colleagues in vitro ${ }^{157}$ and Harvey and coworkers in vivo, ${ }^{156}$ Müller et al. could not find any evidence for the suppression of lymphocyte proliferation in vitro.

Differential effects of OTA on the white blood cell population have also been reported in rabbits. ${ }^{159}$ These authors described an overall reduction in total white blood cell count, which comprised a decrease in granulocytes coupled with an increase in the lymphocyte population. The authors thus concluded OTA to have differential effects on the immune response mediated by bone marrow and lymph nodes. A lack of overt effects on humoral immunity in pigs led to the suggestion that the immune-modulating effects of OTA result from a suppression of lymphocyte blastogenesis and IL-2 production. ${ }^{156,157}$

In one of the most comprehensive studies carried out into the effects of OTA on the murine immune system, Müller and coworkers ${ }^{160}$ demonstrated a generalized depression of almost all of the parameters investigated, although following exposure to the relatively high dose of $3 \mathrm{mg}$ OTA $/ \mathrm{kg} \mathrm{b.w}$. Similarly to the observations made in pigs outlined earlier, these authors demonstrated lymphopenia, neutrophilia, and eosinophilia in mice. Also, although the actual lymphocyte population remained unchanged, the phagocytic activity of neutrophils and monocytes was reduced. An increased production of oxygen radicals by blood leukocytes, which could be responsible for some of the other effects attributed to OTA, was also reported. In agreement with the effect on the humoral immune system reported for pigs by Stoev and coworkers, a significant suppression of the $\operatorname{IgM}$ antibody producing cells in the spleen and a suppression of antibody production in response to Pasturella antigens were evident here and, in an earlier mouse study, ${ }^{161}$ in response to Brucella abortus. In contrast, in the study by Müller and coworkers, administration of raw culture extract did not produce a stronger immune suppressive effect than pure OTA. The effects of OTA on the humoral immune system appear, however, to be subject to huge variations.

Haubeck and coworkers ${ }^{162}$ observed a $50 \%$ decrease in the number of antibody-producing cells in mice following exposure to just $0.005 \mu \mathrm{g}$ OTA $/ \mathrm{kg}$ b.w., whereas a $90 \%$ reduction in plaque-forming cells was reported by another group, after administration of $1 \mu \mathrm{g} / \mathrm{kg}$ b.w. ${ }^{163}$ It appears unlikely that discrepancies of this magnitude can be explained by the use of different mouse strains. Variations in the assays employed or indeed differences in dosage regimens, that is, repeated versus single dose, could conceivably allow for a certain adaptive response to repeated toxin exposure, as has been suggested 
TABLE 2

In vivo effects of OTA on the immune system of various species

\begin{tabular}{|c|c|c|c|}
\hline Species & Dose & Effects & References \\
\hline Pig & $2.5 \mathrm{mg} / \mathrm{kg}$ fodder, 35 days & $\begin{array}{l}\downarrow \mathrm{CBH} ; \downarrow \downarrow \mathrm{DTH} ; \downarrow \downarrow \text { macrophage activity; } \\
\quad \downarrow \text { IL-2 production }\end{array}$ & 156 \\
\hline Pig & $20-50 \mu \mathrm{g} / \mathrm{kg}$ b.w. sc, $28-35$ days & $\begin{array}{l}\uparrow \text { Total leucocyte count; ( } \downarrow \text { lymphocyte } \\
\text { number; } \uparrow \text { neutrophil number); } \\
\downarrow \text { Phagocytic activity of PMN cells }\end{array}$ & 158 \\
\hline Pig & $1-3 \mu \mathrm{g} / \mathrm{kg}$ fodder, 14-21 days & $\begin{array}{l}\uparrow W B C \text { count ( } \downarrow \text { lymphocyte count); } \\
\text { degenerative changes in splenic and } \\
\text { mesenteric lymph nodes; } \uparrow \text { number } \\
\text { of secondary infections; } \\
\downarrow \text { immunization efficiency }\end{array}$ & 161 \\
\hline Mouse & $3 \mathrm{mg} / \mathrm{kg}$ b.w. & $\begin{array}{l}\text { Lymphopenia; neutrophilia; } \\
\text { eosinophilia; } \downarrow \text { phagocytic activity } \\
\text { of neutrophils and monocytes; } \downarrow \text { IgM } \\
\text { response to Pasteurella }\end{array}$ & 160 \\
\hline Mouse & $0.005 \mu \mathrm{g} / \mathrm{kg}$, single dose ip & $\begin{array}{l}\downarrow \text { Number of antibody producing cells } \\
\quad(50 \%)\end{array}$ & 162 \\
\hline Mouse & $1 \mu \mathrm{g} / \mathrm{kg}$ b.w. single dose ip & $\begin{array}{l}\downarrow \text { Number of plaque-forming cells } \\
\quad(90 \%)\end{array}$ & 163 \\
\hline Chick & $\begin{array}{l}130-799 \mu \mathrm{g} / \mathrm{kg} \text { fodder, } \\
7-10 \text { days }\end{array}$ & $\begin{array}{l}\downarrow \text { lymphoid organ weights; } \\
\quad \downarrow \text { Lymphooid cell counts; } \\
\text { } \text { secondary infections; } \\
\downarrow \text { immunization efficiency to } \\
\text { Newcastle disease }\end{array}$ & 166 \\
\hline Chick & $2 \mu \mathrm{g} / \mathrm{kg}$ fodder, 42 days & $\begin{array}{l}\downarrow \text { Immunization efficiency against } \\
\text { Newcastle disease }\end{array}$ & 140 \\
\hline Chick & $4 \mu \mathrm{g} / \mathrm{kg}$ fodder, 20 days & $\downarrow \operatorname{IgG}, \operatorname{IgM}$, and IgA production & 169 \\
\hline Calf & $320-500 \mu \mathrm{g} / \mathrm{kg}$ fodder 87 days & No effect on antibody production & 170 \\
\hline
\end{tabular}

Note. DTH, delayed-type hypersensitivity reaction; $\mathrm{CBH}$, cutaneous basophil hypersensitivity response; ip, intraperitoneal injection; IL, interleukin production; PMN, polymorphonuclear cells; sc, subcutaneous injection; WBC, white blood cells; $\uparrow$, increase in parameter measured as compared with control; $\downarrow$, decrease in parameter measured as compared with control.

for citrinin, ${ }^{164}$ another mycotoxin produced by Aspergillus and Penicillium species. More likely, however, is that the culture extracts from Aspergillus niger NRRL 3174 used in these studies, although isolated and purified via chromatography and the OTA content subsequently measured, may have been contaminated with other mycotoxins with immune-modulating effects. Neither study analyzed the extracts for the presence of other mycotoxins. This, together with different experimental procedures, could explain the differences in the observed responses.

Several of the abovementioned studies also investigated the effects of crude extract from A. ochraceus cultures using the same test systems. Interestingly, with the exception of the slight increase in apoptotic phagocytes following OTA exposure described by Müller and coworkers, the effects of the crude extract were more overt than those observed following administration of pure toxin, despite having comparable levels of OTA. ${ }^{158}$ This was probably as a result of the presence of other substances (mycotoxins) in the crude extract, which may also act in an immunosuppressive manner but were however, not analyzed or identified in these studies.

\section{Practical Considerations of OTA-Mediated Immunotoxicity}

In a more recent study, Stoev and coworkers ${ }^{165}$ investigated the effects of OTA-mediated immune suppression in pigs with respect to subsequent disease susceptibility. These authors reported an increase in the number of white blood cells and a decrease in the lymphocyte population following exposure to fodder contaminated with 1 and $3 \mathrm{mg} / \mathrm{kg}$ OTA. The animals exposed to $3 \mathrm{mg}$ OTA $/ \mathrm{kg}$ fodder rapidly developed salmonellosis, accounting for the observed increase in white blood cells. Degenerative changes were apparent in the lymph follicles of the spleen and mesenteric lymph nodes of both exposure groups. 
Hyperplastic changes in the lymph follicles were only apparent in the higher exposure group, and the authors attributed this to the secondary bacterial infections. Infections with Serpulina hyodysentriae and Campylobacter coli, which were not present in the control cohort, were also apparent in OTA-exposed animals. Furthermore, OTA exposure reduced the efficiency of immunisation against salmonellosis as evidenced by a reduced increase in the number of plaque-forming cells when compared with control animals following immunisation. This was the first report of OTA-mediated decrease in humoral activity in pigs and suggested that the OTA-induced changes in the immune cell populations and activity may represent a large risk for the farming industry, particularly in the current climate of intensive farming.

Further studies have confirmed a role for OTA in the exacerbation of parasitic and microbial disease susceptibility and progression in domestic animals. ${ }^{140,166,167}$ Stoev and coworkers ${ }^{166}$ reported a decrease in the relative weight of the lymphoid organs as well as in the number of lymphoid cells present in the follicles of the bursa Fabricii, thymus, spleen and Peyer's patches in chicks exposed to OTA concentrations ranging from 130 to $790 \mu \mathrm{g} /$ $\mathrm{kg}$ in barley flakes contaminated with an extract of Aspergillus ochraceus. Closer histopathological examination revealed degenerative changes in the germinal centers of the thymus and spleen. An increase in the number of white blood cells was apparent in chicks exposed to 305 and $790 \mu \mathrm{g} / \mathrm{kg}$ OTA. The authors cite secondary infections as the probable cause here. The OTA-exposed chicks also displayed a reduced vaccination immune response to Newcastle disease as measured via haemagglutination inhibition test. This can be attributed to either to a reduction in the proliferation, activation and differentiation of lymphocytes, or an OTA-mediated reduction in protein synthesis, as suggested by previous researchers. ${ }^{168}$ The former appears more likely, as the inhibition of phenylalanine tRNA synthase described by Creppy and coworkers appeared only to become relevant at higher micromolar concentrations of OTA and/or in serum-deprived cells. Furthermore, as mentioned earlier, addition of excess phenylalanine has been demonstrated by other groups working with lower concentrations of OTA (nanomolar) not to have any ameliorating effect on OTA-mediated cytotoxicity. A second study by Stoev further indicated that degeneration of the mucosal epithelium in the jejenum and duodenum following OTA exposure could further increase the susceptibility to coccidiosis. These results were confirmed and complemented in a similar study, ${ }^{140}$ which demonstrated reduced vaccination efficiency against Newcastle disease in chicks exposed to $2 \mathrm{ppm}$ $(2 \mu \mathrm{g} / \mathrm{kg})$ OTA in feed. In all of the mentioned studies, the effects on the immune system were accompanied by histopathological effects in the kidney and liver and partly also by clinical symptoms associated with liver and /or kidney dysfunction.

The highly variable and often contradictory reports of the effects of OTA on the humoral immune system appear to be dependent on the species investigated as well as dose and route of administration. Dwivedi and coworkers ${ }^{169}$ observed a significant reduction of immunoglobulin (Ig) G, IgA, and IgM concen- trations in chickens fed OTA-contaminated grain whereas dietary OTA had no effect on immunoglobulin levels in calves. ${ }^{170}$ Similarly, intraperitoneal injection but not dietary exposure has been shown to suppress antibody responses in mice and guinea pigs. ${ }^{161,171,172}$ The reasons for this are unclear, but it is probably related to the peak concentrations reached following the respective route of administration. Some of the observed effects could be ameliorated by coadministration of phenylalanine (IgM response to sheep red blood cells) ${ }^{162}$ or artichoke extract (antibody response to Newcastle disease inoculation), ${ }^{166}$ with the former suggesting that the immune suppression mediated may result from a competitive inhibition of phenylalanine tRNA synthetase and the latter indicating that faster excretion can reduce the risk of immuno-suppression associated with OTA exposure. In contrast, a protective effect of coadministration of aluminosilicates, which have high adsorbent capacity and ion-exchange capabilities with mycotoxins, could not be demonstrated. ${ }^{140}$

\section{In Vitro Studies}

Unfortunately, there is a dearth of information in the literature as to the mechanism of OTA's immune-modulatory action. Some authors have however attempted to at least begin to analyze this aspect using in vitro techniques. The results of these investigations are summarised in Table 4. Charoenpornsook and coworkers ${ }^{173}$ investigated the ability of OTA to reduce mitogenstimulated proliferation in bovine peripheral blood mononuclear cells (BPM) using four different bioassays: $\left[{ }^{3} \mathrm{H}\right]$ thymidine incorporation, lactate dehydrogenase (LDH) content of intact cells, MTT reduction, and trypan blue exclusion. Of these, $\left[{ }^{3} \mathrm{H}\right]$ thymidine incorporation proved to be the most sensitive. The authors reported OTA to reduce $\left[{ }^{3} \mathrm{H}\right]$ thymidine incorporation into concanavalin A (Con A)-, PHA-, and pokeweed mitogen (PWM)-stimulated BPM with $\mathrm{IC}_{50}$ values of $0.1,0.2$, and $0.15 \mu \mathrm{g} / \mathrm{ml}$, respectively. These experiments were carried out in serum-replete medium, and the concentrations used, while still higher than those of dietary relevance (low nanomolar range), are justifiable in acute toxicity testing. The authors concluded that the immunotoxic effects observed in several studies are the result of an antiproliferative effect of OTA but offered no suggestions as to how this occurs. Unfortunately, the concentration at which the first statistically significant effects became apparent was not mentioned by these authors. An antiproliferative action for OTA has also been described by other authors in primary and in continuous renal cell lines. ${ }^{93}$ Here, although $\mathrm{IC}_{50}$ values were in the micromolar range, first statistically significant reductions in cell numbers as compared to control could be detected at concentrations as low as $1 \mathrm{nM}$ in primary human kidney cells from a female donor.

In a study using EL-4 thyoma cells (ATCC number TIB181) as a model for T cells, Marin and colleagues attempted to correlate the phorbol 12-myristate 13-acetate (PMA)-stimulated production of cytokines with cellular viability and proliferation in the presence of OTA. ${ }^{174} \mathrm{~A}$ reduction in cellular proliferation/viability as assessed by standard MTT reduction assay was 
TABLE 3

In vitro effects of OTA on cells of the immune system

\begin{tabular}{|c|c|c|c|}
\hline System & Parameter and effect & Concentration & References \\
\hline BPM & $\downarrow$ MTT reduction & $\mathrm{n} M-\mu M$ & 173 \\
\hline EL-4 thyoma cells & $\begin{array}{l}\downarrow \text { MTT reduction, } \uparrow \text { IL- } 2, \downarrow \text { IL-5, } \downarrow \text { IL- } 4, \uparrow \text { IL- } 6 \\
\quad \text { (cytokine production) }\end{array}$ & $12.5-25 \mu M$ & 174,175 \\
\hline Human thymocytes & $\downarrow$ IL-2 production, $\downarrow$ IL-2 receptor expression & $12.5-50 \mu M$ & 176 \\
\hline Human B-lymphocytes & $\downarrow$ Response to polyclonal activators & $50 \mu M$ & 176 \\
\hline THP-1 cells & $\begin{array}{l}\downarrow \text { MTT reduction, } \downarrow \text { PI exclusion, } \uparrow(?) \\
\quad \text { Apoptosis }\end{array}$ & $25 \mu M$ & 28 \\
\hline Human lymphocytes & $\begin{array}{l}\text { No SCE } \\
\text { No } \uparrow \text { in micronuclei occurence } \\
\uparrow \text { Micronuclei occurence, } \uparrow \text { number of } \\
\text { binucleated cells }\end{array}$ & $\begin{array}{l}10-25 \mu M \\
100 \mathrm{p} M-10 \mu M \\
\geq 25 \mu M\end{array}$ & $\begin{array}{l}108 \\
110\end{array}$ \\
\hline
\end{tabular}

Note. BPM, bovine peripheral blood mononuclear cells; IL, interleukin production; MTT, [3-(4,5-dimethylthiazol2-yl)-2,5-diphenyltetrazolium bromide]; PI, propidium iodide; $\uparrow$, increase in parameter measured as compared with control; $\downarrow$, decrease in parameter measured as compared with control.

apparent at the relatively high concentration of $25 \mu M$. This was coupled with an increase in IL- 2 and a decrease in IL-5 production at concentrations of $12.5 \mu M$ and above. The observed increase in IL-2 production indicates that OTA may be active in two major second messenger systems, namely, an increase in cytosolic $\mathrm{Ca}^{2+}$ and protein kinase $\mathrm{C}$ (PKC) activation with associated gene activation. The authors suggested that these opposing effects reflect differential effects on the Thelper cell- 1 and -2 populations. Similar results published by Heller and coworkers ${ }^{175}$ further demonstrated OTA to reduce IL-4 and enhance IL-6 production in the EL-4 cell line. These authors also reported stronger effects on the same parameters when crude toxin was used. In contrast, Lea et al. reported IL-2 production and IL-2 receptor expression of activated human T-lymphocytes to be severely impaired following OTA exposure. ${ }^{176}$ Interestingly, preincubation with OTB prevented the inhibitory effect of OTA. Furthermore, the response of highly purified B-lymphocytes to polyclonal activators in vitro was inhibited following exposure to OTA. These authors thus suggested OTA to mediate its immunosuppressive effect via interference with essential processes in cell metabolism, irrespective of lymphocyte population or subpopulation. Whether these variations in response represent speciesspecific differences remains to be established. However, it seems logical to assume that alterations in cytokine production could also contribute to the chronic and progressive renal fibrosis associated with BEN and porcine nephropathies (see Figure 4), hence justifying further research into this aspect.

Müller and colleagues investigated the effects of OTA, OTB, OTC and a variety of fractions from a culture of A. ochraceus and of ochratoxin- $\alpha$ in the human monocyte cell line THP$1 .^{28}$ In contrast to the generally accepted opinion, these authors reported OTC and the crude extract to have the greatest effects on a variety of parameters including metabolic activity (MTT reduction), proliferation (Coulter counting), and membrane integrity (propidium iodide exclusion). Both OTA and the crude culture extract also caused a decrease in cellular NO production, and OTA at a concentration of $1000 \mathrm{ng} /$ $\mathrm{ml}(\sim 25 \mu M)$ was reported to increase apoptosis, as measured via FITC-labeled antibody against annexin, from a basal rate of $5 \%$ to $8 \%$. The significance of this minimal increase is however, questionable. Interestingly, addition of 1-phenylalanine could not ameliorate any of the observed effects. A similar lack of protective action by 1-phenylalanine against the antiproliferative effects of OTA was reported by Schwöbel et al. in the LLC-PK1 porcine kidney cell line, ${ }^{177}$ and by Bruinink et al. in primary embryonic chick cells. ${ }^{178}$

The studies just described represent the first steps in the development of suitable model systems to study the immunotoxic effects of OTA. Far fewer actual mechanistic studies have been carried out. The observation of chromosomal aberrations in lymphocytes of BEN patients, as well as the induction of similar defects in healthy human lymphocytes by $15 \mathrm{n} M$ OTA in vitro, ${ }^{179}$ suggested a potential genotoxic mechanism; however, convincing proof remains to be presented. In summary, OTA appears to be active at a number of levels in the immune system, influencing cellular proliferation and/or death rates, the production of antibodies and cytokines, and possibly moderating phagocytic activity by mechanism(s), which remain to be elucidated. The use of relevant model systems and endpoints is crucial for the investigation of these mechanisms and the pertinent interpretation of the results obtained.

\section{DEVELOPMENTAL TOXICITY}

\section{OTA Causes Specific Developmental Defects}

The first reports of developmental toxicity resulting from OTA exposure appeared in the early 1970s. In one of the first studies, carried out by Hayes and colleagues, ${ }^{180}$ a single ip 
administration of OTA ( $5 \mathrm{mg} / \mathrm{kg}$ b.w.) to pregnant mice between gestation days (GD) 7 and 12 resulted in an increased incidence of malformations, in particular exencephaly and malformations of the eye, face, digits, and tail in the pups. Severe facial/cranial effects, including exencephaly, anopthalmy, microphthalmy, and the presence of an extreme median facial cleft, were apparent in the $5-\mathrm{mg} / \mathrm{kg}$ group. Similar but less severe effects were noted in a group following injection with $3 \mathrm{mg} / \mathrm{kg}$. Both the severity and incidence of the teratogenic effects were observed to be dependent on the gestation day on which the OTA was administered to the dams, with GD 8 being the most sensitive. In contrast, the observed slight increase in mortality did not appear to be dependent on the GD of administration. These results were confirmed and determined to also hold true for rats and hamsters in subsequent studies carried out by the same group, with the most sensitive GD varying between 7 and 10, depending on species. ${ }^{181-183}$ Similar observations of sensitivity windows have been made for other classical teratogens, that interfere with specific developmental processes, including valproic acid, ${ }^{184}$ retinoic acid, ${ }^{185}$ and thalidomide. ${ }^{186}$ Hood and coworkers also reported an increased incidence of necrotic neuroectodermal cells in the brains and eyes of exposed mouse fetuses. Interestingly, no alterations were observed in the expected target organs such as kidney and spleen. However, as the authors suggested, these organs have a relatively high capacity for regeneration, which could have masked effects in these studies, whereas the repair processes in the brain are of a far slower nature. Similar results were reported in mice following a single administration of $8 \mathrm{mg} / \mathrm{kg}$ b.w. OTA via stomach gavage, ${ }^{187}$ although GD 9 was reported as being the most sensitive in this study - possibly due to the natural delay in reaching peak concentration caused by oral instead of ip administration. In addition to the effects described by previous authors, reduced skull and facial bone size and a generalized edema of the facial skin of exposed embryos were noted here. All of these authors described an insensitivity of fetuses to exposure after GD 9. There are two plausible explanations for this: that the closure of the neural pore, which is complete at this stage of gestation, prevents access of the toxin to the target tissues, or secondly, that the amount of toxin crossing the placental barrier is reduced in later gestation stages. Support for the latter was delivered by Appelgren and Arora, who demonstrated the majority of radiolabelled OTA, administered on GD 10 or 17 to remain in the murine uterine wall without gaining access to the developing fetuses. ${ }^{56}$ A similar study by Ballinger and coworkers demonstrated that although OTA can accumulate in the developing fetus, total fetal OTA does not exceed $0.07 \%$ of the administered dose following a single sc injection of the dams on GD 12 with $2.5 \mathrm{mg} / \mathrm{kg}$ b.w. OTA. ${ }^{32}$ Maximum fetal levels were reached $48 \mathrm{~h}$ postdosing in this study, and no evidence of fetal metabolites was found. Furthermore, Mayura and colleagues have also demonstrated a single dose of $1.75 \mathrm{mg} / \mathrm{kg}$ b.w. to cause multiple teratogenic effects in developing rat embryos without coincident deleterious effects in the dams. ${ }^{188}$ Thus, it appears that the terato- genic effects mediated by OTA are caused by a direct action of the parent compound on the developing fetus. The observations of Arora and coworkers ${ }^{189}$ seem to corroborate these observations, as simultaneous administration of diethylstilbestrol and zearalenone, both of which have been shown to reduce transplacental blood flow, resulted in an overall reduction or absence of abnormal fetuses in rats exposed to OTA. In contrast to these reports of teratogenesis in several species, a study carried out by Shreeve and coworkers indicated OTA to have no teratogenic potential in pigs. ${ }^{190}$ It must be mentioned, however, that exposure was only carried out between GD 21 and 28 and OTA could not be detected in fetal tissue, indicating that it is possible that the sensitivity window for placental transfer was not covered in this study.

\section{In Vivo Mechanistic Studies}

Wei and Sulik demonstrated excessive cell death in several regions of developing mouse embryos using Nile blue sulfate histological staining following maternal OTA exposure. ${ }^{191}$ The affected regions included the medial half of the neural plate, the premigratory neural crest cells, the periphery of the anterior neural folds, and, in developmentally slightly more advanced embryos, the periphery of the posterior neural pore. An extreme narrowing of the frontonasal prominence was also apparent, which correlates well with the craniofacial abnormalities described by other authors. Similar results were obtained using chick embryos as model system, also by Wei and Sulik. ${ }^{192}$ The authors described a reduction in somite number in OTA-exposed chicks and extensive cell death in the neural tube region caudal to the last-formed somite but not in the notochord. The majority of the observed cell death was apparent in the ventral regions of the neural tube and in cranial aspects of the primitive streak. Wei and Sulik attributed the abnormalities caused by OTA exposure to excessive cell death in specific embryonal regions, some of which may be involved in directing subsequent developmental stages and suggested free radical generation and/or the inhibition of protein synthesis as candidate mechanisms for future investigation. Support for this theory was provided by the study carried out by Abdel-Wahhab and colleagues, who demonstrated coadministration of 1-methionine to ameliorate the teratogenic effects of OTA in rats and suggested this to be due to a stimulatory effect of 1-methionine on the enzymes involved in DNA and protein synthesis. ${ }^{193}$ However, 1-methionine may also simply have acted as an antioxidant, thus reducing the impact of any free radicals generated following OTA exposure.

Fukui and colleagues ${ }^{194}$ observed deficits in the synapse-toneuron ratio in the brains of mice exposed to OTA in utero, which they reported, contrary to the reports of cell death by several authors, to be due to the presence of an increased number of neurons with each neuron forming fewer synapses. They suggested this to be a result of poor dendritic growth in the developing brain. Support for this was provided by Hong et al., ${ }^{195}$ who demonstrated OTA to reduce neurite outgrowth in cultured 
rat embryonic midbrain cells with $\mathrm{IC}_{50}$ values of approximately $1.1 \mu M$.

\section{In Vitro Studies}

Clear cytotoxic effects of OTA in cultured cells of neuronal origin in vitro have been reported and purported to be the cause of the microcephaly observed following in utero exposure. Indeed, Monnet-Tschudi and co-workers ${ }^{196}$ demonstrated this to occur at nanomolar concentrations, in a time-dependent manner. In this study, employing aggregating cell cultures of fetal rat telencephalon, cells from earlier developmental periods were more sensitive to the effects of OTA. These in vitro effects can probably be attributed to the parent compound, as Bruinink and colleagues demonstrated OTA and OTB solutions to be stable at $36.5^{\circ} \mathrm{C}$ over at least 7 days. ${ }^{178}$ It is currently not clear if these effects are of a selective ${ }^{197}$ or general nature. ${ }^{198}$ A study carried out by Hong and coworkers attempted to address some of these issues. ${ }^{195}$ The authors assessed OTA-mediated cytotoxicity and cell differentiation in cultured rat embryonic midbrain (dopaminergic) and limb bud cells (nondopaminergic). OTA was observed to reduce $\left[{ }^{3} \mathrm{H}\right]$ thymidine incorporation, cellular protein content, cell viability, and glutathione levels in both cell types, with midbrain cells being only minimally more sensitive. These effects could not be abrogated by the addition of exogenous glutathione. No difference was apparent in the $\mathrm{IC}_{50}$ values determined for the two cell types for any of the parameters tested. Thus the authors concluded that if indeed OTA possesses a selective toxicity for particular neuron types, then this is at least not based on the dopaminergic/nondopaminergic nature of those cells. Bruinink et al. concluded that OTA does not possess a specific neurotoxic action, as cell cultures of embryonic chick brain, neural retina, and meninges displayed similar responses to nanomolar concentrations. ${ }^{178}$ Similarly to previous findings, OTB was observed to be approximately 10 -fold less toxic than OTA in this study, and the effects of OTA could not be reversed by addition of 1-phenylalanine.

As for all of the toxic actions of OTA, the mechanism of its neurotoxicity remains controversial and requires extensive further research in suitable model systems. Although certain free-radical scavengers such as indol-3-carbinol, superoxide dismuthase, and catalase could not prevent OTA-mediated cytotoxicity in midbrain cells, ${ }^{199}$ many more antioxidants must be tested before a role for free radical generation in OTA-mediated neurotoxicity can be dismissed.

In a subsequent study, also carried out in cultured rat embryonic midbrain cells, Hong and coworkers demonstrated OTA to increase the activation of the transcription factors AP-1 and NF- $\kappa$ B. ${ }^{200}$ This could be prevented via stimulation of PPAR- $\gamma$ activation by 15 -deoxy- $\Delta^{12,14}$-prostaglandin $\mathrm{J}_{2}$ (15-deoxy $\mathrm{PGJ}_{2}$ ). Although this suggests the involvement of the PPAR- $\gamma$ pathway in the toxicity of OTA, a direct alteration of either basal or 15-deoxy $\mathrm{PGJ}_{2}$-stimulated PPAR $-\gamma$ activity by OTA could not be demonstrated. The acknowledged effects of PPAR- $\gamma$ on macrophage activa- tion and cytokine production via antagonism of the AP-1 and NF- $\kappa \mathrm{B}$ pathways make these findings worthy of further investigation.

The majority of mechanistic or model-based studies, aimed at investigating the teratogenic mechanism of action of OTA have concentrated on the two areas where the starkest effects have been noted, namely, the brain and related neural systems, and the skeleton. Using prechondrogenic mesenchymal cells from chick embryo limb buds, Wiger and Stormer demonstrated ochratoxins to inhibit the accumulation of cartilage proteoglycans and general protein synthesis in a dose-dependent manner with $\mathrm{IC}_{50}$ values of 1.9 and $6.2 \mu M$ for OTA and OTB, respectively. ${ }^{201}$ As no metabolites could be detected, the authors attributed the effects to the parent substances. In contrast to the results obtained in peripheral T lymphocytes by the same group, ${ }^{176}$ preincubation of the micromass cultures with OTB had no moderating effect on the outcome of OTA incubations. This underlines once more the need for the use of appropriate model systems for mechanistic research.

The frog embryo teratogenicity assay Xenopus (FETAX) could present one such possibility, as it provides a useful tool for the generation of samples for mechanistic studies. Embryos of the South African clawed frog (Xenopus laevis) have, in agreement with the effects described for all other species tested to date, been demonstrated to be sensitive to the teratogenic effects of OTA, with craniofacial narrowing being the characteristic abnormality $\left(\mathrm{EC}_{50}=60 \mathrm{nM}\right){ }^{202} \mathrm{Em}$ bryos exposed to higher concentrations (>200 $\mathrm{nM}$ ) displayed up to $20 \%$ growth inhibition when compared with controls. The craniofacial effects following OTA exposure appeared to be of a specific nature in contrast to those apparent following exposure to OTB, which were accompanied by incomplete gut coiling. Furthermore, no significant decrease in embryo length was evident following exposure to OTB, and the concentrations required to induce malformation were approximately fourfold higher than that observed for OTA (O'Brien et al., manuscript in preparation). Thus, this simple and rapid (96 h) assay system can differentiate between the two highly similar structural analogs and should be considered for future investigations.

\section{HEPATOTOXICITY}

Although OTA has been reported to cause hepatocellular carcinoma in mice, ${ }^{55}$ reports dealing with the hepatotoxic and the hepatocellular carcinoma promoting potential of OTA are much rarer than those dealing with nephrotoxic, immunotoxic, or teratogenic effects. Most reports are purely descriptive in nature and deal with case studies of ochratoxicoses occurring in poultry farms where the feed was massively contaminated. One study, however, expanded on such a case study in geese, goslings, and broilers and carried out a feeding experiment with OTAcontaminated (110-930 ng/g OTA) and with OTA-free grain. ${ }^{203}$ These investigators also analyzed the complete feed and several of its individual components for the presence of several of the 
most common mycotoxins in an attempt to determine which mycotoxin could be responsible for the observed pathology. This screen (detection limits as $\mathrm{ng} / \mathrm{g}$ in parentheses) included OTA (20), citrinin (100), aflatoxin (10), T-2 toxin (50), HT-2 toxin (50), diacetoxyscirpenol (50), neosolaniol (100), zearalenone (50), deoxynivalenol (50), roridin (250), and verrucarin (250). Only OTA was detected in the samples. Both species presented with multifocal hepatic necrosis, which was more diffuse in broilers and more extensive in goslings. Several geese also displayed bacterial colonies at the necrotic sites. This could be indicative of an immune suppression concurrent with the observed hepatotoxicity. Amyloidosis was also seen in some of the older birds. Slight nephropathies were observed in broilers; however, these were deemed to be of lesser importance with respect to their contribution to the overall intoxication symptoms. These results were in complete contrast to those reported in another study carried out in the chick model, where the primary pathology was nephrosis. ${ }^{204}$ Based on their analysis of the grain samples, where no other known mycotoxin could be found, the authors of the former paper attributed the hepatotoxicity to the presence of OTA and at least one other as yet unknown mycotoxin. Serious problems become apparent however, when one considers the huge variation in the concentrations of OTA detected. These values ranged from less than $20 \mathrm{ng} / \mathrm{g}$ to $410 \mathrm{ng} / \mathrm{g}$ in subsamples of the same sample.

In a more recent and better controlled study, Atroshi and coworkers examined the effects of acute OTA toxicity on the activity of several enzymes commonly used as sensitive markers of hepatocellular necrosis in humans. ${ }^{205}$ These authors demonstrated a significantly increased activity of aspartate amino transferase (ASAT), alanine aminotransferase (ALAT), and alkaline phosphatase (AP) but not $1-\gamma$-glutamyl transferase $(\gamma-\mathrm{GT})$ in the livers of rats given a single dose of $2.5 \mathrm{mg} / \mathrm{kg}$ b.w. via gastric intubation. Pretreatment with tamoxifen reduced the observed increase in ASAT and indeed prevented any increase in ALAT and AP. In contrast, pretreatment with vitamin $\mathrm{E}$ and selenium had no effect on the observed increase in ASAT or ALAT activity, but did prevent the OTA-associated increase in AP, and indeed, animals pretreated with vitamin $\mathrm{E}$ and selenium actually displayed a lower $\gamma$-GT activity than their corresponding controls. Unfortunately, neither pathological examinations of the livers nor free radical measurement was carried out in this study, so that a direct link between the generation of free radicals and subsequent pathological changes could not be established. However, the protective effects of vitamin $\mathrm{E}$ and selenium could indeed point future research in this direction.

Stoev et al. described moderate liver degeneration with graywhite foci, accompanied by swelling of both the capillary endothelium and Kupffer's cells. ${ }^{165}$ Biochemically, these effects could be correlated with increased urinary $\gamma$-GT activity and serum ASAT, ALAT, ALD, and AlkPh activities, which could be associated with degenerative changes in either the kidney or the liver, in pigs following exposure to fodder containing $3 \mu \mathrm{g} / \mathrm{kg}$ OTA. However, despite descriptive reports of OTA-mediated hepatoxicity and evidence that OTA can accumulate in the liver as well as in the kidney, ${ }^{206}$ attempts to define the mechanism of OTA-mediated hepatotoxicity have been relatively few and far between, and those that have been carried out have yielded inconclusive and often highly contradictory results.

\section{SYNERGISTIC EFFECTS WITH OTHER MYCOTOXINS}

A recent publication by Stoev and coworkers ${ }^{62}$ cast at least some doubt on the role of OTA as the sole cause of the pathological effects observed in Bulgarian cases of porcine nephropathy. Based on experiments in 3- to 12-month-old pigs, these authors suggest that the observed renal effects may result from exposure to a combination of different nephrotoxic mycotoxins including penicillic acid and citrinin, which are also produced by Penicillium species. The authors described differences in the renal pathologies resulting from OTA exposure alone and those observed following a combination of two or more other mycotoxins. Further studies must be carried out in order to clarify this question. However, it appears logical to assume that exposure to several nephrotoxic substances could have more severe consequences than exposure to a single substance. Indeed initial cytotoxicity studies with a range of known nephrotoxic mycotoxins in vitro have indicated certain combinations to be more toxic than the sum of their individual actions (Heussner, manuscript submitted).

\section{CURRENT STATUS AND FUTURE PERSPECTIVES}

Any proposed mechanism of action should aim to explain all of the effects observed both in vivo and in vitro, as has been achived for fumonisin $\mathrm{B}_{1}$ and aflatoxin $\mathrm{A}$. Despite the fact that the effects of ochratoxins in domestic and laboratory animals have been extensively documented, the mechanism of action remains elusive. A definitive causal link to Balkan endemic nephropathy and the etiology of the characteristic urothelial tumors also remain to be established. The effects of ochratoxins have massive socioeconomic implications, which make the elucidation of the mechanism of action of this intangible toxin imperative. This can only be achieved through the use of a combination of well-designed in vivo and in vitro experiments with the goal of identifying the initial event in the chain leading to carcinogenesis and renal fibrosis.

The obvious contradictions and differences in the reported mechanism(s) appear to be indicative of the large variations in cell type- and species-dependent differences characteristic of OTA-mediated toxicity. The optimization of experimental design is crucial if progress is to be made in this area. Suitable, reliable cell model systems must be generated and the effects of chronic OTA exposure on the earliest possible markers of renal carcinogenesis must be investigated, for example, using DNA chip technologies, in order to achieve a trustworthy human risk assessment. The crucial issues of dose/exposure concentrations and of presence or absence of serum in these experimental systems, as described in this review, must also be considered in 
future investigations. Based on the sex- and species-specific differences in toxicity, it is logical to look for these models in relevant species and to compare in vitro and in vivo effects. As primary cells of human and porcine origin have proven to be the most sensitive so far, it appears reasonable to support further and more detailed research in this area.

Continuing research in the area of organic anion transporters with respect to their relevance for OTA toxicity is a necessity, such that the cellular kinetics may be better understood. Moreover, the determination of which, if any, of these proteins is responsible for intracellular OTA accumulation could prove critical in determining the reasons for the diversity of toxic effects and hence, the mode of action. This is of particular relevance with respect to determining possible increased risk of OTA toxicity in children, which has been suggested in report published by Wolff and coworkers ${ }^{207}$ to be higher than in adults. The observations made by Buist and colleagues ${ }^{96,97}$ that the expression patterns of certain OATs vary considerably with age, at least in the rat, lend support to the need for extensive research in this area. Thus, cell model systems and in particular primary cells should be characterized for their transporter protein complement and should have this correlated with their ability to accumulate OTA. As intracellular OTA accumulation alone is insufficient to define the sensitivity of a particular cell type to OTA-mediated cytotoxicity, the differences in the response of a variety of related cell types, for example, NRK-52E and NRK-49F and primary human renal epithelial cells and fibroblasts, not to mention transformed cells, as well as the marked differences in response to the structural analogue OTB, must be considered in any mechanistic study.

\section{GENOTOXIC OR NONGENOTOXIC: WHAT'S IN A NAME?}

This question has kept hundreds of researchers at work for decades, and although progress has been made, there is still a long way to go to finally find the answer. Genotoxic chemicals are those capable of causing damage to DNA. Unfortunately, this term has come to have another, more widely accepted definition, which is very restrictive and moreover incorrect: namely, that the substance in question has a direct effect on the DNA. This direct interaction leads, for example, to the generation of DNA adducts, sister chromatid exchange, loss of heterozygosity, etc., although even these may result from an initial "simple" cytotoxicity. A return to the broader view of the definition of genotoxicity, which accepts that DNA damage must not necessarily result from a direct interaction between the substance and DNA, must be made in order to avoid personal biases in the investigation of the toxicity of specific substances. These early upstream events and also the observed kinetics and dose-response considerations outlined in this review are much more likely to be species and/or sex specific and so to be crucial for risk assessment. Thus, when one's aim is the definition of the initial event in OTA-mediated toxicity, be that renal, hepatic, immunological, or developmental, the relevant parameters must be analyzed. Furthermore, it is highly likely that a distancing from the current thinking of a strict delineation between genotoxic and nongenotoxic effects may prove more rewarding in the search for the mechanism of OTA-mediated toxicity.

\section{REFERENCES}

1. Bhatnagar, D., Kenneth, J. W., and Ehrlich, K. C. (2002). Toxins of filamentous fungi, in Fungal allergyand pathogenicity, Vol. 81, M. Breitenbach, R. Crameri, and S. B. Lehrer, eds., Basel, Karger, 167.

2. Stormer, F.C. (1995). Does ochratoxin A prevent iron uptake in bacteria?, 7th Nordic Mycotoxin Meeting, Oslo, Norway, O24.

3. Stormer, F.C., and Hoiby, E.A. (1996). Citrinin, ochratoxin A and iron. Possible implications for their biological function and induction of nephropathy. Mycopathologia 134:103.

4. IARC (1993). Ochratoxin A, in Some naturally occurring substances: Food items and constituents, heterocyclic aromatic amines and mycotoxins Vol. 56, IARC and WHO, eds., Lyon, IARC, WHO, 489.

5. Park, D.L., and Troxell, T.C. (2002). U.S. perspective on mycotoxin regulatory issues, in Mycotoxins and food safety, Vol. 504, J.W. DeVries, M. W. Trucksess, and L.B. Jackson, eds., SummitArga, Kluwer Academic/Plenum, 277.

6. JEFCA (1995). Evaluation of certain food additives and contaminants, Joint FAO/WHO Expert Committee on food additives, 35.

7. European Commission (1997). Assessment of dietary intake of ochratoxin A by the population of EU member states. Reports of Task Force on Scientific Co-operation.

8. CCFAC (2001). Draft code for the prevention of mycotoxin contamination in cereals. Food and Agriculture Organization of the United Nations (www.fao.org/docrep/meeting/005/y0474e/ y0474e0w. htm).

9. Viglione, P. (1998). Contamination of red wine with ochratoxin A (Elintarvikevirasto jyräsi salailevan Alkon), in Ilta-Sanomat Abo-Turku, A8.

10. Claiborne Ray, C. (2001). Peanut perils?, in New York Times 15.05.2001, late edition, New York, 2.

11. Mrasek, V. (2002). Zu viel Pilzgifte in Pasta und Polenta (Too many mycotoxins in pasta and polenta), in Frankfurter Rundschau, 29.10.2002, Frankfurt am Main.

12. Bassen, B., and Brunn, W. (1999). Ochratoxin A in Paprikapulver (Ochratoxin in paprika powder). Deutsche lebensmittelRundschau 95(4): 142.

13. Spiegel, D. (2001). Pilzgift im Lakritz (Mycotoxin in liquorisch), Spiegel Online (www.spiegel.de/spiegel/vorab/0,1518,111022, 00.html).

14. Warentest, S. (2001). Leichter NachgeschmackSchimmelpilzgift in löslichen Kaffee (Slight aftertasteMycotoxins in instant coffee powder), in Test 8:82.

15. Leong, S.L. (2003). Wine woman and song (http://www. theasm.com.au/nsw).

16. Marquardt, R.R., and Frohlich, A. (1990). Ochratoxin a: An important western Canadian storage mycotoxin. Can. J. Physiol. Pharmacol. 68:991. 
17. Frisvad, J.C., and Samson, R.A. (1991). Mycotoxins produced in species of Penicillium and Aspergillus occurring in cereals, in Cereal grain mycotoxins, Fungi and quality in drying and storage, J. Chelkowsik, ed., Amsterdam, Elsivier, 441.

18. Schuster, E., Dunn-Coleman, N., Frisvad, J.C., and Van Dijck (2002). P.W., On the safety of Aspergillus niger-A review, Applied Microbial Biotechnology 59(4-5):426.

19. Scott, P.M., Van Walbeck, W., Kennedy, B., and Anyeti, D. (1972). Mycotoxins (ochratoxin A, citrinin and sterigmatocystin) and toxigenic fungi in grains and agricultural products. J. Agric. Food Chem. 20:1103.

20. Abramson, D., Mills, J.T., and Sinha, R.N. (1990). Mycotoxin production in amber durum wheat stored at 15 and 19\% moisture content. Food Additives and Contaminants 7(5):617.

21. Ramos, A.J., Labernia, N., Marin, S., Sanchis, V., and Magan, N. (1998). Effect of water activity and temperature on growth and ochratoxin production by three strains of Aspergillus ochraceus on an barley extract medium and on barley grains. Int. J. Food Microbiol 44(1-2): 133 .

22. Berry, L. (1988). The pathology of mycotoxins. Journal of Pathology 154:301.

23. Puntaric, D., Bosnir, J., Smit, Z., and Baklaic, Z. (2001). Ochratoxin A in corn and wheat: Geographical association with endemic nephropathy. Croatian Medical Journal 42(2):175.

24. Majerus, P., and Otteneder, H. (1996). Nachweis und vorkommen on Ochratoxin A in Wein und Traubensaft. Deutsche Lebensmittel-Rundschau 92(12):388.

25. van der Merwe, K.J., Steyn, P.S., Fourie, L., Scott, D.B., and Theron, J.J. (1965). Ochratoxin A, a toxic metabolite produced by Aspergillus ochraceus Wilh. Nature 205(4976):1112.

26. van der Merwe, K.J., Steyn, P.S., and Fourie, L., Mycotoxins. Part II. The constitution of ochratoxin A, B, and C, metabolites of Aspergillus ochraceus Wilh. Journal of the Chemical Society 7038: 1965 .

27. Li, S., Marquardt, R.R., Frohlich, A.A., Vitti, T.G., and Crow, G. (1997). Pharmacokinetics of ochratoxin A and its metabolites in rats. Toxicology and Applied Pharmacology 145:82.

28. Müller, G., Rosner, H., Rohrmann, B., Erler, W., Geschwend, G., Grafe, U., Burkert, B., Moller, U., Diller, R., and Sachse, K. (2003). Effects of the mycotoxin ochratoxin A and some of its metabolites on the human cell line THP-1. Toxicology 184(1):69.

29. Hagelberg, S., Hult, K., and and Fuchs, R. (1989). Toxicokinetics of ochratoxin A in several species and its plasma-binding properties. Journal of Applied Toxicology 9(2):91.

30. Galtier, P., Alvinerie, M., and Charpenteau, J.L. (1981). The Pharmacokinetic profiles of ochratoxin A in pigs, rabbits and chickens. Food and Cosmetics Toxicology 19:735.

31. Mortensen, H.P., Hald, B., and Madsen, A. (1983). Feeding experiments with ochratoxin A contaminated barley for bacon pigs: 5. Ochratoxin A in pig blood. Acta Agriculturae Scandinavica 33: 235.

32. Ballinger, M.B., Phillips, T.D., and Kubena, L.F. (1986). Assessment of the distribution and elimination of ochratoxin a in the pregnant rat. Journal of Food Safety 8:11.

33. Galtier, P., Charpenteau, J.-L., Alvinerie, M., and Labouche, C. (1979). The pharmacokinetic profile of ochratoxin A in the rat after oral and intravenous administration. Drug Metabolism and Disposition 7(6):429.
34. Fukui, Y., Hoshino, K., Kameyama, Y., Yasui, T., Toda, C., and Nagano, H. (1987). Placental transfer of ochratoxin A and its cytotoxic effect on the mouse embryonic brain. Food and Chemical Toxicology 25:17.

35. JEFCA (2001). Ochratoxin A, Joint FAO/WHO Expert Committee on food additives, 10.

36. Peraica, M., Radic, B., Lucic, A., and Pavlovic, M. (1999). Diseases caused by molds in humans vol. 2003. Health and Energy.

37. Krogh, P., Elling, F., Gyrd-Hansen, N., Hald, B., Larsen, A.E., Lillehoj, E.B., Madsen, A., Mortensen, H.P., and Ravnskov, U. (1976). Experimental porcine nephropathy: Changes of renal function and structure perorally induced by crystalline ochratoxin A. Acta Pathologica Microbiologica Scandinavica Section A 84:429.

38. Stoev, S.D., Stoeva, J.K., Anguelov, G., Hald, B., Creppy, E.E., and Radic, B. (1998). Haematological, biochemical and toxicological investigations in spontaneous cases with different frequency of porcine nephropathy in Bulgaria. Zentralbl. Veterinarmed. A 45(4):229.

39. Marquardt, R.R., and Frohlich, A.A. (1992). A review of recent advances in understanding ochratoxicosis. Journal of Animal Science 70:3968.

40. Danilovic, V., Djurisic, M., Stojimirovic, B., Zivojinovic, J., and Stojakovic, P. (1957). Nephrites chronique provoquees par l'intoxication au plomb par voie digestive (farine). Presse Med. 65:2039.

41. Tatu, C.A., Orem, W.H., R.B., F., and Feder, G.L. (1998). The etiology of Balkan endemic nephropathy: Still more questions than answers. Environmental Health Perspectives 106(11):689.

42. Djukanovic, L., Radovic, M., Bakovic, J., Budosan, I., Bukvic, D., Cveticanin, A., Davinic, S., Dragoljic, B., Djordjevic, V., Djuric, S., Haviza-Lilic, M., Janos, B., Jelacic, S., Kostic, N., Mandic, M., Ostric, V., Pljesa, S., Radisic, M., Radojevic, M., Rakic, N., Rangelov, V., Stojanovic, M., Tintor, D., and Vasic, V. (2002). Epidemiology of end-stage renal disease and current status of hemodialysis in Yugoslavia. Int. J. Artif. Organs 25(9):852.

43. Vukelic, M., Sostaric, B., and Fuchs, R. (1991). Some pathomorphological features of Balkan endemic nephropathy in Croatia, in Mycotoxins, endemic nephropathy and urinary tract tumours, vol. 115, M. Castegarno, R. Plestina, G. Dirheimer, I.N. Chernozemsky, and H. Bartsch, eds., Lyons, IARC Scientific, 37.

44. Sostaric, B., and Vukelic, M. (1991). Characteristics of urinary tract tumours in the area of Balkan endemic nephropathy in Croatia, in Mycotoxins, endemic nephropathy and urinary tract tumours, vol. 115, M. Castegnaro, R. Plestina, G. Dirheimer, I.N. Chernozemsky, and H. Bartsch, eds., Lyons, IARC Scientific, 29.

45. Abdelhamid, A.M. (1990). Occurrence of some mycotoxins (aflatoxin, ochratoxin A, citrinin, zearalenon and vomitoxin) in variours Egyptian feeds. Archive in Animal Nutrition 40(7):647.

46. Maaroufi, K., Achour, A., Hammami, M., el May, M., Betheder, A.M., Ellouz, F., Creppy, E.E., and Bacha, H. (1995). Ochratoxin A in human blood in relation to nephropathy in Tunisia. Hum. Exp. Toxicol. 14:609.

47. Maaroufi, K., Achour, A., Betbeder, A.-M., Hammami, M., Ellouz, F., Creppy, E.E., and Bacha, H. (1995). Foodstuffs and human blood contamination by the mycotoxin ochratoxin A: Correlation with chronic interstitial nephropathy in Tunisia. Arch. Toxicol. 69:552. 
48. Radic, B., Fuchs, R., Peraica, M., and Lucic, A. (1997). Ochratoxin A in human sera in the area with endemic nephropathy in Croatia. Toxicology Letters 91:105.

49. Fillastre, J.-P. (1997). Néphrotoxicité expérimentale et humaine des ochratoxines. Bull. Acad. Natl. Méd 181(7):1447.

50. Kuiper-Goodmann, T. (1999). Approaches to the risk analysis of mycotoxins in the food supply. Food, Nutrition and Agriculture 23:10.

51. Stoev, S.D., Hald, B., and Mantle, P.G. (1998). Porcine nephropathy in Bulgaria: A progressive syndrome of complex or uncertain (mycotoxin) aetiology. Vet. Rec, 142(8):190.

52. Elling, F. (1979). Ochratoxin A-induced mycotoxic porcine nephropathy: Alterations in enzyme activity in tubular cells. Acta Pathologica Microbiologica Scandinavica Sect. A 87A(4):237.

53. Elling, F. (1983). Feeding experiments with ochratoxin Acontaminated barley to bacon pigs. Acta Agric Scand 33:153.

54. Boorman, g.A., McDonald, M.R., Imoto, S., and Persing, R. (1992). Renal lesions induced by ochratoxin A exposure in the F344 rat. Toxicologic Pathology 20(2):236.

55. Bendele, A.M., Carlton, W.W., Krogh, E.B., and Lillehoj, E.B. (1985). Ochratoxin A carcinogenesis in the $\left(\mathrm{C} 57 \mathrm{BL} / \& \mathrm{~J} \mathrm{X} \mathrm{C}^{*} \mathrm{H}\right) \mathrm{F}_{1}$ mouse. Journal of the National Cancer Institute 75(4):733.

56. Appelgren, L.-E., and Arora, R.G. (1983). Distribution of ${ }^{14} \mathrm{C}$ labelled ochratoxinA in pregnant mice. Food Chem. Toxicol. 21(5):563.

57. Fuchs, R., Appelgren, L.-E., and Hult, K. (1988). Distribution of ${ }^{14} \mathrm{C}$-Ochratoxin $\mathrm{A}$ in the mouse monitored by whole-body autoradiography. Pharmacol. Toxicol. 63:355.

58. Fuchs, R., and Hult, K. (1992). Ochratoxin A in blood and its pharmacokinetic properties. Food Chem. Toxic. 30(3):201.

59. DFG (1990). Ochratoxin A, Vorkommen und toxikologische Bewertung. Deutsche Forschungsgemeinschaft.

60. Studer-Rohr, J., Schlatter, J., and Dietrich, D.R. (2000). Intraindividual variation in plasma levels and kinetic parameters of ochratoxin A in humans. Arch. Toxicol. 74(9):499.

61. Curtui, V.G., Gareis, M., Usleber, E., and Martlbauer, E. (2001). Survey of Romanian slaughterd pigs for the occurrence of mycotoxins A and B, and zearalenone. Food Addit. Contam. 18(8):730.

62. Stoev, S.D., Paskalev, M., MacDonald, S., and Mantle, P.G. (2002). Experimental one year ochratoxicosis in pigs. Experimental and Toxicological Pathology 53:481.

63. Özcelik, N., Kosar, A., and Soysal, D. (2001). Ochratoxin in human serum samples collected in Isparta, Turkey, from healthy individuals and individuals suffering from different urinary disorders. Toxicol. Lett. 121(1):9.

64. Filali, A., Betbeder, A.-M., Baudrimont, I., Benyad, A., and Soulaymani, R. (2002). Ochratoxin A in human plasma in Morocco: A preliminary survey. Hum. Exp. Toxicol. 21(5):241.

65. Abid, S., Hassen, W., Achour, A., Skhiri, H., Ellouz, F., Creppy, E.E., and Bacha, H. (2003). Ochratoxin A and human chronic nephropathy in Tunisia: Is the situation endemic? Hum. Exp. Toxicol. 22(2):77.

66. Peraica, M., Domijan, A.M., Fuchs, R., Lucic, A., and Radic, B. (1999). The occurrence of ochratoxin A in blood in general population of Croatia. Toxicol. Lett. 110:105.

67. Nikolov, I.G., Petkova-Bocharova, D., Castegnaro, M., PfohlLeskowicz, A., Gill, C., Day, N., and Chernozemsky, I.N. (1996). Molecular and epidemiological approaches to the etiology of uri- nary tract tumors in an area with Balkan endemic nephropathy. J. Environ. Pathol. Toxicol. Oncol. 15(2-4):201.

68. Galtier, P. (1978). Contribution of pharmacokinetic studies to mycotoxicology-Ochratoxin A. Veterinary Science Communications 1:349.

69. Hult, K., and Fuchs, F. (1986). Analysis and dynamics of ochratoxin A in biological systems, in Mycotoxins and Phycotoxins, P.S. Steyn and R. Vleggaar, eds., Amsterdam, Elsevier Science, 365 .

70. Kumagai, S. (1985). Ochratoxin A: Plasma concentration and excretion into bile and urine in albumin-deficient rats. Food Chem. Toxicol. 23(10):941.

71. Kumagai, S., and Aibara, K. (1982). Intestinal absorption and secretion of ochratoxin A in the rat. Toxicology and Applied Pharmacology 64:94.

72. Kuiper-Goodman, T., and Scott, P.M. (1989). Risk assessment of the mycotoxin ochratoxin A. Biomedical and Environmental Sciences 2(3): 179 .

73. Sreemannarayana, O., Frohlich, A.A., Vitti, T.G., Maryuardt, R.R., and Abramson, D. (1988). Studies of the tolerance and disposition of ochratoxin A in young calves. Journal of Animal Science 66: 1703 .

74. Roth, A., Chakor, K., Creppy, E.E., Kane, A., Röschenthaler, R., and Dirheimer, G. (1988). Evidence for an enterohepatic circulation of ochratoxin A in mice. Toxicology 48:293.

75. Fuchs, R., Radic, B., Paraica, M., Hult, K., and Plestina, R. (1988). Enterohepatic circulation of ochratoxin A in rats. Period. Biol. 90(1):39.

76. Stein, A.F., Phillips, T.D., Kubena, L.F., and Harvey, R.B. (1985). Renal tubular secretion and readsorption as factors in ochratoxicosis: Effects of probenicid on nephrotoxicity. J. Toxicol. Environ. Health 16:593.

77. Albassam, M.A., Yong, S.I., Bhatnagar, R., Sharma, A.K., and Prior, M.G. (1987). Histological and electron microscopic studies on the acute toxicity of ochratoxin A in rats. Vet. Pathol. 24: 427 ,

78. Størmer, F.C., Hansen, C.E., Pedersen, J.I., Hvistendahl, G., and Aasen, A.J. (1981). Formation of (4R)- and (4S)-4hydroxyochratoxin A from ochratoxin A by liver microsomes from various species. Appl. Environ. Microbiol. 42(6):1051.

79. Pitout, M.J. (1969). The hydrolysis of ochratoxin A by some proteolytic enzymes. Biochemical Pharmacology 18:485.

80. Hansen, C.E., Dueland, S., Drevon, C.A., and Stormer, F.C. (1982). Metabolism of ochratoxin A by primary cultures of rat hepatocytes. Appl. Environm. Microbiol. 43(6):1267.

81. Støren, O., Holm, H., and Størmer, F.C. (1982). Metabolism of ochratoxin A by rats. Applied and Environmental Microbiology 44(4): 785

82. Moroi, K., Suzuki, S., Kuga, T., Yamazaki, M., and Kanisawa, M. (1985). Induction of ochratoxin A toxicity in mice treated with phenylalanine and phenolbarbital. Toxicology Letters 25:1.

83. Stander, M.A., Nieuwouldt, T.W., Steyn, P.S., Shepard, G.S., Creppy, E.E., and Sewram, V. (2001). Toxicokinetics of ochratoxin A in vervet monkeys (Chercopithecus aethiops). Arch. Toxicol. 75:262.

84. Vedani, A., and Bruinink, A. (1996). Ochratoxin A und B: Ein dreidimensionales molekulares Modell zur mechanistischen Erklärung ihrer Toxizität (Ochratoxin A and B: A 
three-dimensional molecular model for a mechanistic explanation of their toxicity). ALTEX 13(3): 124.

85. Heussner, A.H., O'Brien, E., and Dietrich, D.R. (2002). Speciesand sex-specific variations in binding of ochratoxin A by renal proteins in vitro Exp. Toxicol. Pathol. 54:151.

86. Tsuda, M., Sekine, T., Takeda, M., Cha, S.H., Kanai, Y., Kimura, M., and Endou, H. (1999). Transport of ochratoxin A by renal multispecific organic anion transporter 1. Journal of Pharmacology and Experimental Therapeutics 289:1301.

87. Il'ichev, Y.V., Perry, J.L., Rüker, F., Dockal, M., and Simon, J.D. (2002). Interaction of ochratoxin A with human binding sites localized by competitive interactions with native protein and its recombinant fragments. Chemico-Biological Interactions 141:275.

88. Russel, F.G.M., Masereeuw, R., and van Aubel, R.A.M.H. (2002). Molecular aspects of renal anionic drug transport. Annu. Rev. Physiol. 64:563.

89. Masereeuw, R., and Russel, F.G.M., Mechanisms and clinical implications in renal drug excretion. Drug. Metab. Rev. 33(34):299.

90. Sokol, P.P., Ripich, G., Holohan, P.D., and Ross, C.R. (1988) Mechanism of ochratoxin A transport in kidney. J. Pharmacol. Exp. Ther. 246(2):460.

91. Gekle, M., Mildenberger, S., Freudinger, R., and Silbernagel, S. (1994). The mycotoxin ochratoxin A impairs protein uptake in cells derived from the proximal tubule of the kidney (opossum kidney cells). J. Pharmacol. Exp. Ther. 271:1.

92. Groves, C.E., Morales, M., and Wright, S.H. (1998). Peritubular transport of ochratoxin A in rabbit renal proximal tubules. Journal of Pharmacology and Experimental Therapeutics 284(3):943.

93. O'Brien, E., Heussner, A.H., and Dietrich, D. (2001). Species-, sex- and cell type specific effects of ochratoxin A and B. Toxicological Sciences 63:256.

94. Jung, K.Y., Takeda, M., Kim, D.K., Tojo, A., Narikawa, S., Yoo, B.S., Hosoyamada, M., Cha, S.H., Sekine, T., and Endou, H. (2001). Characterization of ochratoxin A transport by human organic anion transporters. Life Sciences 69:2123.

95. Babu, E., Takeda, M., Narikawa, S., Kobayashi, Y., Enomoto, A., Tojo, A., Cha, S.H., Sekine, T., Sakthisekaran, D., and Endou, H. (2002). Role of human anio transporter 4 in the transport of ochratoxin A. Biochimica et Biophysica Acta 1590:64.

96. Buist, S.C.N., and Klaassen, C.D. (2003). Species and gender differences inorganic anion transporter (OAT) mRNA. Toxicological Sciences (The Toxicologist) 72(S-1):259.

97. Buist, S.C.N. (2002). Gender-specific and developmental influences on the expression of rat organic anion transporters. Journal of pharmacology and experimental therapeutics 301:145.

98. Dreger, S., O'Brien, E., Satck, M., and Dietrich, D. (2000). Antiproliferative effects and cell-cycle specific effects of ochratoxin A in LLC-PK1, NRK-52E and porcine primary proximal kidney cells. Toxicological Sciences 54(1): 170 .

99. Obrecht-Pflumio, S., Chassat, T., Dirheimer, G., and Marzin, D. (1999). Genotoxicity of ochratoxin A by Salmonella mutagenicity test after bioactivation by mouse kidney microsomes. Mutat. Res. 446(1):95.

100. Föllmann, W., and Lucas, S. (2003). Effects of ochratoxin A in a bacterial and a mammalian in vitro mutagenicity test system. Archives in toxicology 77:298.
101. Föllmann, W., Hillebrand, I.E., Creppy, E.E., and Bolt, H.M (1995). Sister chromatid exchange frequency in cultured isolated porcine urinary bladder epithelial cells (PUBEC) treated with ochratoxin A and alpha. Arch. Toxicol. 69:280.

102. Doerrenhaus, A., Flieger, A., Golka, K., Schulze, H., Albrecht, M., Degen, G.H., and Follman, W. (2000). Induction of unscheduled DNA synthesis in primary human urothelial cells by the mycotoxin ochratoxin A. Toxicological Sciences 53:271.

103. Rahimtula, A.D., Bereziat, J.C., Bussacchini, G.V., and Bartsch, H. (1988). Lipid peroxidation as a possible cause of ochratoxin A toxicity. Biochemical Pharmacology 37(23):4469.

104. Schwerdt, G., Freudinger, R., Mildenberger, S., Silbernagl, S., and Gekle, M. (1999). The nephrotoxin ochratoxin A induces apoptosis in cultured human proximal tubule cells. Cell Biology and Toxicology 15(6):405.

105. Horvath, A., Upham, B.L., Ganev, V., and Trosko, J.E. (2002). Determination of the epigenetic effects of ochratoxin in a human kidney and a rat liver epithelial cell line. Toxicon 40:273.

106. Degen, G.H. (1997). Induction of micronuclei with ochratoxin A in ovine seminal vesicle cell cultures. Archives in Toxicology 71:365.

107. Dopp, E., Muller, J., Hahnel, C., and Schiffmann, D. (1999). Induction of genotoxic effects and modulation of the intracellular calcium level in Syrian hamster embryo (SHE) fibroblasts caused by ochratoxin A. Food and Chemical Toxicology 37(7):713.

108. Cooray, R., Kiessling, K.H., and Lindahl-Kiessling, K. (1982). The effects of patulin and patulin-cystein mixtures on DNA synthesis and the frequency of sister-chromatid exchanges in human lymphocytes. Food Chem. Toxicol. 20:893.

109. Bendele, A.M., Neal, S.B., Oberly, T.J., Thompson, C.Z., Bewsey, B.J., Hill, L.E., Rexroat, M.A., Carlton, W.W., and Probst, G.S. (1985). Evaluation of ochratoxin A for mutagenicity in a battery of bacterial and mammalian cell assays. Food Chem. Toxicol. 23:911.

110. Donmez-Altuntas, H., Hamurcu, Z., Imamoglu, N., and Liman, B.C. (2003). Effects of ochratoxin A on micronucleus frequency in human lymphocytes. Nahrung 47(1):33.

111. Ehrlich, V., Darroudi, F., Uhl, M., Steinkellner, H., Gann, M., Majer, B.J., Eisenbauer, M., and Knasmüller, S. (2002). Genotoxic effects of ochratoxin A in human-derived hepatoma (HepG2) cells. Food and Chemical Toxicology 40:1085.

112. Fuchs, R., Radic, B., Ceovic, S., Sostaric, B., and Hult, K. (1991). Human exposure to ochratoxin A, in Mycotoxins, endemic nephropathy and urinary tract tumours, vol. 115, M. Castegnaro, R. Plestina, G. Dirheimer, I.N. Chernozemsky, and H. Bartsch, eds., Lyon, International Agency for Research on Cancer, 131.

113. Palli, D., Miraglia, M., Saieva, C., Masala, G., Cava, E., Colatosti, M., Corsi, A.M., Russo, A., and Brera, C. (1999). Serum levels of of OTA in healthy adults in Tuscany: Correlation with individual characteristics and between repeat measurements. Cancer Epidemiology. Biomarkers and Prevention 8:265.

114. Gross-Steinmeyer, K., Weymann, J., Hege, H.-G., and Metzler, M. (2002). Metabolism and lack of DNA reactivity of the mycotoxin ochratoxin A in cultured rat and human primary hepatocytes. Journal of Agricultural and Food Chemistry 50:938.

115. Zepnik, H., Pahler, A., Schauer, U., and Dekant, W. (2001). Ochratoxin A-induced tumor formation: Is there a role of reactive ochratoxin A metabolites? Toxicol. Sci. 59(1):59. 
116. Gautier, J., Richoz, J., Welti, D.H., Markovic, J., Gremaud, E., Guengerich, F.P., and Turesky, R.J. (2001). Metabolism of ochratoxin A: Absence of formation of genotoxic derivatives by human and rat enzymes. Chem. Res. Toxicol. 14(1):34.

117. Creppy, E.E., Kane, A., Dirheimer, G., Lafarge-Frayssinet, C., Mousset, S., and Frayssinet, C. (1985). Genotoxicity of ochratoxin A in mice: DNA single-strand break evaluation in spleen, liver and kidney. Toxicology Letters 28:29.

118. Pfohl-Leszkowicz, A., Chakor, K., Creppy, E.E., and Dirheimer, G. (1991). DNA adduct formation in mice treated with ochratoxin A, in Mycotoxins, endemic nephropathy and urinary tract tumours, vol. 115, M. Castegnaro, R. Plestina, G. Dirheimer, I.N. Chernozemsky, and H. Bartsch, eds., Lyon, International Agency for Research on Cancer, 245.

119. Pfohl-Leszkowicz, A., Grosse, Y., Kane, A., Creppy, E.E., and Dirheimer, G. (1993). Differential DNA adduct formation and disappearance in three mouse tissues after treatment with the mycotoxin ochratoxin A. Mutation Research 289:265.

120. Castegnaro, M., Mohr, U., Pfohl-Leszkowicz, A., Esteve, J., Steinmann, J., Tillman, T., Michelon, J., and Bartsch, H. (1998). Sex- and strain-specific induction of renal tumours by ochratoxin A in rats correlates with DNA adduction. Int. J. Cancer 77(1):70.

121. Obecht-Pflumio, S., and Dirheimer, G. (2001). Horseradish peroxidase mediates DNA and deoxyguanosine 3 '-monophosphate adduct formation in the presence of ochratoxin A. Archives of Toxicology.

122. Gautier, J.-C., Holzhaeuser, D., Markovic, J., Gremaud, E., Schilter, B., and Turesky, R.J. (2001). Oxidative damage and stress response from ochratoxin A exosure in rats. Free Radical Biology \& Medicine 30(10): 1089.

123. Dai, J., Wright, M.W., and Manderville, R.A. (2003). Ochratoxin forms a carbon-bonded C8-deoxyguanosine nucleoside adduct: Implications for $\mathrm{C} 8$ reactivity by a phenolic radical. Journal of the American Chemical Society 125:3715.

124. Gillman, I.G., Clark, T.N., and Manderville, R.A. (1999). Oxidation of ochratoxin A by an Fe-porphyrin system: Model for enzymatic activation and DNA cleavage. Chemical Research in Toxicology 12: 1066.

125. Dai, J., Park, G., Wright, M.W., Adams, M., Akman, S.A., and Manderville, R.A. (2002). Detection and characterization of a glutathione conjugate of ochratoxin A. Chemical Research in Toxicology 15:1581.

126. Creppy, E.E., Lugnier, A.A.J., Beck, G., Röschenthaler, R., and Dirheimer, G. (1979). Action of ochratoxin A on cultured hepatoma cells-Reversion of inhibition by phenylalanine. FEBS Letters 104(2): 287.

127. Creppy, E.E., Lugnier, A.A.J., Fasiolo, f., Heller, K., Röschenthaler, R., and Dirheimer, G. (1979). In vitro inhibition of yeast phenylalanyl-tRNA synthetase by ochratoxin A. ChemicoBiological Interactions 24:257.

128. Omar, R.F., Hasinoff, B.B., Mejilla, F., and Rahimtula, A.D. (1990). Mechanism of ochratoxin a stimulated lipid peroxidation. Biochemical Pharmacology 40(6): 1183.

129. Omar, R.F., and Rahimtula, A.D. (1991). Role of cytochrom P450 in ochratoxin A-stimulated lipid peroxidarion. J. Biochem. Toxicology 6(3):203.

130. Heussner, A., Schwöbel, F., and Dietrich, D.R. (1998). Cytotoxicity of ochratoxin A and B in vitro: Comparison of male and female rat primary renal cortex and distal cells and LLC-PK1 cells. Toxicological Sciences 42:1416.

131. Petrik, J., Zanic-Grubisic, T., Barisic, K., Pepeljnjak, S., Radic, B., Ferencic, Z., and Cepelak, I. (2003). Apoptosis and oxidative stress induced by ochratoxin A in rat kidney. Archives in Toxicology 77:685.

132. Omar, R.F., Hasinoff, B.B., Mejilla, F., and Rahimtula, A.D. (1990). Mechanism of ochratoxin A stimulated lipid peroxidation. Biochemical Pharmacology 40(6): 1183.

133. Meki, A.R.M.A., and Hussein, A.A.A. (2001). Melatonin reduces oxidative stress induced by ochratoxin A in rat liver and kidney. Comparative Biochemistry and Physiology Part C 130: 305.

134. Schaaf, G.J., Nujmeijer, S.M., Maas, R.F.M., Roestenberg, P., De Groene, E.M., and Fink-Gremmels, J. (2002). The role of oxidative stress in the ochratoxin A-mediated toxicity in proximal tubular cells. Biochimica et Biophysica Acta 1588: 149.

135. Hoehler, D., and Marquardt, R.R. (1996). Influence of vitamins E and $\mathrm{C}$ on the toxic effects of ochratoxin a and T-2 toxin in chicks. Poultry Science 75:1508.

136. Hoehler, D., Marquardt, R.R., McIntosh, A.R., and Xiao, H. (1996). Free radical generation as induced by ochratoxin $A$ and its analogs in bacteria (Bacillus brevis). Journal of Biological Chemistry 271(44):27388.

137. Hoehler, D., Marquardt, R.R., McIntosh, A.R., and Hatch, G.M. (1997). Induction of free radicals in hepatocytes, mitochondria and microsomes of rats by ochratoxin A and its analogs. Biochimica et Biophysica Acta 1357:225.

138. Obrecht-Pflumio, S., Grosse, Y., Pfohl-Leszkowicz, A., and Dirheimer, G. (1996). Protection by indomethacin and aspirin against genotoxicity of ochratoxin A, particularly in the urinary bladder and kidney. Arch. Toxicol. 70(3-4):244.

139. Grosse, Y., Chekir-Ghedira, L., Huc, A., Obrecht-Pflumio, S., Dirheimer, G., Bacha, H., and Pfohl-Leszkowicz, A. (1997). Retinol, ascorbic acid and alpha-tocopherol prevent DNA adduct formation in mice treated with the mycotoxins ochratoxin A and zearalenone. Cancer Lett. 114(1-2):225.

140. Santin, E., Paulillio, A.C., Maiorka, P.C., Alessi, A.C., Krabbe, E.L., and Maiorka, A. (2002). The effects of ochratoxin/aluminosilicate interaction on the tissues and humoral response of broilers. Avian Pathology 31:73.

141. Moore, J.H., and Truelove, B. (1970). Ochratoxin A: Inhibition of mitochondrial respiration. Science 168: 1102.

142. Meisner, H., and Chan, S. (1974). Ochratoxin A, an inhibitor of mitochondrial transport system. Biochemistry 13(14): 2795.

143. Wei, Y.-H., Lu, C.-Y., Lin, T.-N., and Wei, R.-D. (1985). Effect of ochratoxin A on rat liver mitochondrial respiration and oxidative phosphorylation. Toxicology 36:119.

144. Eder, S., Benesic, A., Freudinger, R., Engert, J., Schwerdt, G., Drumm, K., and Gekle, M. (2000). Nephritogenic ochratoxin A interfers with mitochondrial function and $\mathrm{pH}$ homeostasis in immortalized human kidney epithelial cells. Pflügers Arch. Eur. J. Physiol. online, published DOI 10.1007/s004240000321.

145. Heller, M., Rosner, H., Burkert, B., Moller, U., Hinsching, A., Rohrmann, B., Thierbach, S., and Kohler, H. (2002). In vitro studies into the influence of ochratoxin A on the production of tumor necrosis factor alpha by the human monocytic cell line THP-1. Deutsche Tierarztliche Wochenschrift 109(4):200. 
146. Luhe, A., Hildebrand, H., Bach, U., Dingerman, T., and Ahr, H.-J. (2003). A new approach to studying ochratoxin A (OTA)induced nephrotoxicity: Expression profiling in vivo and in vitro employing cDNA microarrays. Toxicological Sciences 73:315.

147. Gekle, M., Schwerdt, G., Freudinger, R., Mildenberger, S., Wilflingseder, D., Pollack, V., Dander, M., and Schramek, H. (2000). Ochratoxin A induces JNK activation and apoptosis in MDCK-C7 cells at nanomolar concentrations. Journal of Pharmacology and Experimental Therapeutics 293(3):837.

148. Gennari, A., Boveri, M., Pazos, P., Callaghan, R., Casado, J., and Prieto, P. (2003). Cellular and molecular mechanisms underlying ochratoxin A-induced in vitro nephrotoxicity, Toxicological Sciences (The Toxicologist) 72(S-1):348.

149. Assaf, H., Azouri, H., and Pallardy, M. (2003). Mechanisms of ochratoxin A-induced inhibition of human lymphocyte proliferation. Toxicological Sciences (The Toxicologist) 72(S-1):358.

150. Seegers, J.C. (1994). A comparative study of ochratoxin Ainduced apoptosis in hamster kidney and HeLa cells. Toxicology and Applied Pharmacology 129:1.

151. Wolf, P., O’Brien, E., Heussner, A.H., Stack, M.E., Thiel, R., and Dietrich, D.R. (2002). Sex- and age-specific effects of ochratoxin A in primary human kidney cells (HKC). Toxicological Sciences 66(1-S):400.

152. Heussner, A., Stack, M., Hochberg, K., and Dietrich, D. (2000). Comparison of cytotoxic effects of ochratoxin A and B on human, rat and porcine renal cells. Toxicological Sciences 54(1):170.

153. Rásonyi, T., Schlatter, J., and Dietrich, D.R. (1999). The role of $\alpha 2 \mu$-globulin in ochratoxin A induced renal toxicity and tumors in F344 rats. Toxicology Letters 104:83.

154. Gekle, M., Oberleithner, H., and Silbernagl, S. (1993). Ochratoxin A impairs "postproximal" nephron function in vivo and blocks plasma membrane anion conductance in Madin-Darby canine kidney cells in vitro. Pflügers Archiv European Journal of Physiology 425:401.

155. Barisic, K., Petrick, J., Rumora, L., Cepelak, I., and Zanic Grubisic, T. (2002). Expression of Hsp70 in kidney cells exposed to ochratoxin A. Molecular Toxicology 76:218.

156. Harvey, R.B., Elissalde, M.H., Kubena, L.F., Weaver, E.A., and Corrier, D.E. (1992). Immunotoxicity of ochratoxin A to growing gilts. American Journal of Veterinary Research 53(10): 1966.

157. Holmberg, T., Thuvander, A., and Hult, K. (1988). Ochratoxin A as a suppressor of mitogen-induced blastogenesis of porcine blood lymphocytes. Acta Vet. Scandinavica 29:219.

158. Müller, G., Kielstein, P., Rosner, H., Berndt, A., Heller, M., and Kohler, H. (1999). Studies of the influence of ochratoxin A on immune and defence reactions in weaners. Mycoses 42(7-8):495.

159. Verma, R.J., and Mathew, S. (1998). Alterations in total and differential counts of WBC during ochratoxicosis in rabbits. Indian Journal of Experimental Biology 36:424.

160. Müller, G., Kielstein, P., Köhler, H., Berndt, A., and Rosner, H. (1995). Studies on the influence of ochratoxin A on immune and defence reactions in the mouse model. Mycoses 38:85.

161. Prior, M.G., and Sisodia, C.S. (1982). The effects of ochratoxin A on the immune system in Swiss mice. Can. J. Comp. Med. 46:91.

162. Haubeck, H.-D., Lorkowski, G., Koelsch, E., and Roeschenthaler, R. (1981). Immunosuppression by ochratoxin A and its prevention by phenylalanine. Appl. Environm. Microbiol. 41(4):1040.
163. Creppy, E.E., Stormer, F.C., Roeschenthaler, R., and Dirheimer, G. (1983). Effects of two metabolites of ochratoxin A, (4R)-4hydroxyochratoxin A and ochratoxin alpha, on immune response in mice. Infection and Immunity 39(3): 1015.

164. Jordan, W.H., and Carlton, W.W. (1977). Citrinin mycotoxicosis in the mouse. Food and Cosmetic Toxicology 15:29.

165. Stoev, S.D., Goundasheva, D., Mirtcheva, T., and Mantle, P.G. (2000). Susceptibility to secondary bacterial infections in growing pigs as an early response in ochratoxicosis. Experimental and Toxicological Pathology 52:287.

166. Stoev, S.D., Anguelov, G., and Pavlov, D. 2000. Influences of ochratoxin A and an extract of artichoke on the vaccinal immunity and health in broiler chicks. Experimental and Toxicological Pathology 52:43.

167. Stoev, S.D., Koynarsky, V., and Mantle, P.G. (2002). Clinicomorphological studies in chicks fed ochratoxin A while simultaneoulsy developing coccidosis. Veterinary research Communications 26:189.

168. Creppy, E.E., Kern, D., Steyn, P.S., Vleggaar, R., Röschenthaler, R., and Dirheimer, G. (1983). Comparative study on the effect of ochratoxin A analogues on yeast aminoacyl-tRNA synthetases and on the growth and protein synthesis of hepatoma cells. Toxicology Letters 19:217.

169. Dwivedi, P. (1984). Effect of ochratoxin A on immunoglobulins in broiler chicks. Research in Veterinary Science 36:117.

170. Patterson, D.S.P., Shreeve, B.J., and Roberts, B.A. (1981). Effect on claves of barley naturally contaminated with ochratoxin A and groundnut meal contaminated with low concentrations of aflatoxin $\mathrm{B}_{1}$. Research in Veterinary Science 31:213.

171. Richard, J.L., Thurston, J.R., and Deyse, B.L. (1975). Effect of ochratoxin and aflatoxin on serum proteins, complement activity and antibody production to Brucella abortus in guinea pigs. Applied and Environmental Microbiology 29:27.

172. Creppy, E.E., Stormer, C.F., Röschenthaler, R.T., and Dirheimer, G. (1983). Effects of two metabolites of ochratoxin A, (4R)-4hydroxyochratoxin A and ochratoxin alpha, on immune response in mice. Infection and Immunity 39:1015.

173. Charoenpornsook, K., Fitzpatrick, J.L., and Smith, J.E. (1998). The effects of four mycotoxins on the mitogen stimulated proliferation of bovine peripheral blood mononuclear cells in vitro. Mycopathologia 143:105.

174. Marin, M.L., Murtha, J., Dong, W., and Pestka, J.J. (1996). Effects of mycotoxins on cytokine production and proliferation in EL-4 thyoma cells. Journal of Toxicology and Environmental Health 48:379.

175. Heller, M., Köhler, H., Rosner, H., Burkert, B., Rohrmann, B., Möller, U., Thierbach, S., Kielstein, P., and Müller, G. (2000). Beeinflussung der Zytokinsekretion von Maus-Thyomzellen (EL4) durch ochratoxin. Mycotoxin Research 16A:194.

176. Lea, T., Steien, K., and Stormer, F.C. (1989). Mechanism of ochratoxin A-induced immunosuppression. Mycopathologia 107(23): 153 .

177. Schwöbel, F., O'Brien, E., and Dietrich, D.R., Ochratoxin A (OTA) reversibly inhibits proliferation in the LLCPK-1 cell line, Toxicol. Sci. 1999.

178. Bruinink, A., Rasonyi, T., and Sidler, C. (1997). Reduction of ochratoxin A toxicity by heat-induced epimerization. In vitro effects of ochratoxins on embryonic chick meningeal and other cell cultures. Toxicology 118:205. 
179. Manolov, G., Manolova, Y., Castegnaro, M., and Chernozemsky, I.N. (1991). Chromosomal alterations in lymphocytes of patients with Balkan endemic nephropathy and of healthy individuals after incubationin vitro with ochratoxin A, in Mycotoxins, endemic nephropathy and urinary tract tumours vol. 115, M. Castegnaro, R. Plestina, G. Dirheimer, I.N. Chernozemsky, and H. Bartsch, eds., Lyon, International Agency for Research on Cancer, 267.

180. Hayes, A.W., Hood, R.D., and Lee, H.L. (1973). Teratogenic effects of ochratoxin A in mice. Teratology 9:93.

181. Hayes, A.W., Hood, R.D., and Lee, H.L. (1974). Teratogenic effects of ochratoxin A in mice. Teratology 9:93.

182. Hood, R.D., Naughton, M.J., and Hays, A.W. (1976). Prenatal effects of ochratoxin A in hamsters. Teratology 13:11.

183. Brown, M.H., Szczech, G.M., and Purmalis, B.P. (1976). Teratogenic and toxic effects of ochratoxin A in rats. Toxicol. Appl. Pharmacol. 37:331.

184. Ehlers, K., Sturge, H., Merker, H.J., and Nau, H. (1992). Spina bifida aperta induced by valproic acid in the mouse: Distinct differences in morphology and periods of sensitivity. Teratology 48: 117.

185. Krätke, R., Rühl, R., Kirschbaum, F., and Nau, H. (2000). Alltrans-retinoic acid and all-trans-retinoyl-b-d-glucuronide alter the development of axolotl embryos (Ambystoma mexicanum) in vitro. Archives in Toxicology 74:173.

186. Nowak, E. (1965). Die sensible Phase bei der TahlidomideEmbryopathie. Humangenetik 1:516.

187. Arora, R.G., Frölèn, H., and Nilsson, A. (1981). Interference of mycotoxins with prenatal development of the mouse I. Influence of aflatoxin B1, ochratoxin A and zearalenone. Acta Vet. Scand. 22:524.

188. Mayura, K., Parker, R., Berndt, W.O., and Phillips, T.D. (1984). Ochratoxin A-induced teratogenesis in rats: Partial protection by phenylalanine. Appl. Environm. Microbiol. 48(6): 1186.

189. Arora, R.G., Froelein, H., and Fellner-Feldegg, H. (1983). Inhibition of ochratoxin A teratogenesis by zearalenone and diethylstilboestrol. Fundamentals in Chemical Toxicology 21(6): 779.

190. Shreeve, B.J., Patterson, S.P., Pepin, G.A., Roberts, B.A., and Wrathall, A.E. (1977). Effect of feeding ochratoxin to pigs during early pregnancy. British Veterinary Journal 133:412.

191. Wei, X., and Sulik, K.K. (1993). Pathogenesis of craniofacial and body wall malformations induced by ochratoxin A in mice. American Journal of Medical Genetics 47:862.

192. Wei, X., and Sulik, K.K. (1996). Pathogenesis of caudal dysgenesis/sirenomelia induced by ochratoxin A in chick embryos. Teratology 53:378.

193. Abdel-Wahhab, M.A., Nada, S.A., and Arbid, M.S. (1999). Ochratoxicosis: Prevention of developmental toxicity by 1methionine in rats. Journal of Applied Toxicology 19:(7).

194. Fukui, Y., Hayasaka, S., Itoh, M., and Takeuchi, Y. (1992). Development of neurons and synapses in ochratoxin A-induced microcephalic mice: A quantitative assessment of somatosensory cortex. Neurotoxicology and Teratology 14:191.

195. Hong, J.T., Park, K.L., Han, S.Y., Park, K.S., Kim, H.S., Oh, S.D., Lee, R.D., and Jang, S.J. (2000). Effects of ochratoxin A on cytotoxicity and cell differentiation in cultured rat embryonic cells. J. Toxicol. Environ. Health A 61(7):609.
196. Monnet-Tschudi, F., Sorg, O., Honegger, P., Zurich, M.-G., Huggett, A.C., and Schilter, B. (1997). Effects of the naturally occurring food mycotoxin ochratoxin a on brain cells in culture. NeuroToxicology 18(3):831.

197. Belmadani, A., Tramu, G., Betbeder, A.-M., Steyn, P.S., and Creppy, E.E. (1998). Regional selectivity to ochratoxin A, distribution and cytotoxicity in rat brain. Arch. Toxicol. 72:656662.

198. Bruinink, A., and Sidler, C. (1997). The neurotoxic effects of ochratoxin-A are reduced by protein binding but are not affected by $l$-phenylalanine. Toxicology and Applied Pharmacology 146: 173

199. Han, S.Y., Park, K.S., Hong, J.T., Kim, H.S., Oh, S.D., Kook, S.S., and Jang, S.J. (1998). Ochratoxin A-induced embryotoxicity and preventive effect of catalase in cultured rat embryonic midbrain cells. Teratology 59:403.

200. Hong, J.T., Lee, M.K., Park, K.S., Jung, K.M., Lee, R.D., Jung, H.K., Park, K.L., Yang, K.H., and Chung, S.Y. (2002). Inhibitory effects of peroxisome proliferator-activated receptor gamma agonist on ochratoxin A-induced cytotoxicity and activation of transcription factors in cultured rat embryonic midbrain cells. Journal of Toxicology and Environmental Health 65:407.

201. Wiger, R., and Størmer, F.C. (1990). Effects of ochratoxin A and $\mathrm{B}$ on prechondrogenic mensenchymal cells from chick embryo limb buds. Toxicology Letters 54:129.

202. O'Brien, E., Prietz, A., and Dietrich, D.R. (1999). Characterisation of ochratoxin A uptake and developmental toxicity using the FETAX system. Toxicological Sciences 43(S1):150.

203. Shlosberg, A., Elkin, N., Malkinson, M., Orgad, U., Hanji, V., Bogin, E., Weisman, Y., Meroz, M., and Bock, R. (1997). Severe hepatopathy in geese and broilers associated with ochratoxin in their feed. Mycopathologia 138:71.

204. Peckham, J.C., Doupnik, B., and Jones, O.H. (1971). Acute toxicity of ochratoxin A and B in chicks. Appl. Microbiol. 21:492.

205. Atroshi, F., Rizzo, A., Sankari, S., Biese, I., Westermarck, T., and Veijalainen, P. (2000). Liver and enzyme activities of rats exposed to ochratoxin A and T-2 toxin with antioxidants. Bull. Environ. Contam. Toxicol. 64:586.

206. Biro, K., Solzi, L., Barna-Vetro, I., Bago, G., Glavits, R., Szabo, E., and Fink-Gremels, J. (2002). Tissue distribution of ochratoxin A as determined by HPLC and ELISA and histopatological effects in chickens. Avian Pathology 31:141-148.

207. Wolff, J., Bresch, H., Cholmakow-Bodechtel, C., Engel, G., Erhardt, S., Gareis, M., Majerus, P., Rosner, H., and Scheuer, R. (2000). Belastung des Verbrauchers und der Lebensmittel mit Ochratoxin A, forschungsverbund Produkt-und Ernährungsforschung des Bundesministeriums für Ernährung. Landwirtschaft und Forsten 243.

208. Cihlar, T., Lin, D.C., Pritchard, J.B., Fuller, M.D., Mendel, D.B., and Sweet, D.H. (1999). The antiviral nucleotide analogs cidofovir and adefovir are novel substrates for human and rat renal organic anion transporter 1. Mol. Pharmacol. 56:570.

209. Hosoyamada, M., Sekine, T., Kanai, Y., and Endou, H. (1999). Molecular cloning and functional expression of a multipsecific organic anion transporter from human kidney. Am. J. Physiol. Renal Physiol. 276:F122.

210. Lu, R., Chan, B.S, and Schuster, V.L. (1999). Cloning of the human kidney PAH transporter: Narrow substrate specificity and 
regulation by protein kinase C. Am. J. Physiol. Renal Physiol. 276:F295.

211. Kojima, Sekine, T.R., Kawachi, M., Cha, S. H., Suzuki, Y., and Endou, H. (2002). Immunolocalization of multispecific organic anion transporters, OAT1, OAT2 and OAT3 in rat kidney. J. Am. Soc. Nephrol. 13:848.

212. Sweet, D.H., Wolff, N.A., and Pritchard, J.B. (1997). Expression cloning and characterization of ROAT1. The basloateral organic anion transporter in rat kidney. J.Biol. Chem. 272: 30088.

213. Sekine, T., Watanabe, N., Hosoyamada, M., Kanai, Y., and Endou, H. (1997). Expression cloning and characterization of a novel multispecific anion transporter. J. Biol. Chem. 272: 18526.

214. Uwai, Y., Okuda, M., Takami, K., Hashimoto, Y., and Inui, K.I. (1998). Functional characterization of the rat multispecific organic anion transporter Oat1 mediating basolateral uptake of anionic drugs in the kidney. FEBS Lett. 438:321.

215. Jariyawat, S., Sekine, T., Takeda, M., Apiwattanakul, N., Kanai, Y., et al. (1999). The interaction and transport of beta-lactam antibiotics with the cloned rat renal organic anion transporter. J. Pharmacol. Exp. Ther. 290:672.

216. Apiwattanakul, N., Sekine, T., Chairoungdua, A., Kanai, Y., and Nakajima, N., et al. (1999). Transport proterties of nonsteroidal anti-inflammatory drugs by organic anion transporter1 expressed in Xenopus laevis oocytes. Mol. Pharmacol. 55: 847.

217. Wada, S., Tsuda, M., Sekine, T., Cha, S. H., Kimura, M., et al. (2000). Rat multispecific organic anion transporter 1 (rOAT1) transports zidovudine, acyclovir and other antiviral nucleoside analogs. J. Pharmacol. Exp. Ther. 294:844.

218. Sun, W., Wu, R.R., van Poelje, P.D., and Erion, M.D. (2001). Isolation of a family of organic anion transporters from human liver and kidney. Biochem. Biophys. Res. Commun. 283:417.

219. Sekine, T., Cha, S. H., Tsuda, M., Apiwattanakul, N., Nakajima, M., et al. (1998). Identification of multispecific organic anion transporter expressed predominantly in the liver. FEBS Lett. 429:179.

220. Cha, S. H., Sekine, T., Fukishima, J.I., Kanai, Y., Kobayashi, Y., et al. (2001). Identification and characterization of human organic anion transporter 3 expressing predominantly in the kidney. Mol. Pharmacol. 59:1277.

221. Takeuchi, A., Masuda, S., Saito, H., Abe, T., and Inui, K.I. (2001). Multispecific substrate recognition of kidney-specific organic anion transporters OAT-K1 and OAT-K2. J. Pharmacol. Exp. Ther. 299:261.

222. Kusuhara, H., Sekine, T., Utsunomiya-Tata, N., Tsuda, M., Kojima, R., et al. (1999). Molecular cloning and characterization of a new multispecific organic anion transporter from rat brain. $J$. Biol. Chem. 274:13675.

223. Sweet, D.H., Chan, L.M., Walden, R., Yang, X.P., Miller, D.S., and Pritchard, J.B. (2003). Organic anion transporter 3 (Slc22a8) is a dicarboxylate exchanger indirectly coupled to the $\mathrm{Na}^{+}$gradient. Am. J. Physiol. Renal Physiol. 284:F763.

224. Cha, S. H., Sekine, T., Kusuhara, H., Yu, E., Kim, J.Y., et al. (2000). Molecular cloning and characteritation of multispecific organic anion transporter 4 expressed in the placenta. J. Biol. Chem. 275:4507. 